University of Louisville

ThinkIR: The University of Louisville's Institutional Repository

Electronic Theses and Dissertations

6-1945

\title{
Heat transfer to fuel oil in viscous flow-characteristics of a fin- type heat exchanger.
}

Boyd R. Abbott Jr.

University of Louisville

Follow this and additional works at: https://ir.library.louisville.edu/etd

Part of the Chemical Engineering Commons

\section{Recommended Citation}

Abbott, Boyd R. Jr., "Heat transfer to fuel oil in viscous flow-characteristics of a fin-type heat exchanger." (1945). Electronic Theses and Dissertations. Paper 1856.

https://doi.org/10.18297/etd/1856

This Master's Thesis is brought to you for free and open access by ThinkIR: The University of Louisville's Institutional Repository. It has been accepted for inclusion in Electronic Theses and Dissertations by an authorized administrator of ThinkIR: The University of Louisville's Institutional Repository. This title appears here courtesy of the author, who has retained all other copyrights. For more information, please contact thinkir@louisville.edu. 


\title{
UNIVERSITY OF LOUISVILLE
}

HEAT TRANSFER TO FUEL OIL IN VISCOUS FLOW1

CHARACTERISTICS OF A FIN-TYPE HEAT EXCHANGER

\author{
A Thesis \\ Submitted to the Faculty \\ of the Graduate School \\ of the University of Louisville \\ in Partial Fulfillment \\ of the Requirements \\ for the Degree of
}

MASTER OF CHEMICAL ENGINEERING

Department of Chemioal Engineering

Boyd $R_{h}^{N b b o t t, ~ I r . ~}$

1945 
HEAT TRANSFER TO FUEL OIL IN VISCOUS FLOWCHARACTERISTICS OF A FIN-TYPE HEAT EXCHANGER

Boyd R. Abbott, Jr.

Approved by the Examining Comittee:

Director

June, 1945 
CONTENTS

Page

List of Tables . . . . . . . . . . . . . . . . . . ii List of Figures . . . . . . . . . . . . . . . . . . 1i1 Abstract . . . . . . . . . . . . . . . . . . . . iv Introduction . . . . . . . . . . . . . . . . . . 1 Historical . . . . . . . . . . . . . . . . . . 4 Theoretical . . . . . . . . . . . . . . . . 10 Experimental . . . . . . . . . . . . . . . . . 25 Apparatus . . . . . . . . . . . . . . . 26 Procedure . . . . . . . . . . . . . . . 34 Results. . . . . . . . . . . . . . . . . 37 Discussion . . . . . . . . . . . . . . . 64 Summary and Conclusions . . . . . . . . . . . . . . 71 Literature Cited . . . . . . . . . . . . . . . . 74 Appendix . . . . . . . . . . . . . . . . 76 List of Symbols . . . . . . . . . . . . . . 77 Sample Calculations . . . . . . . . . . . 80 Acknowledgment . . . . . . . . . . . . . . . . . . 92 Vita . . . . . . . . . . . . . . . . . . . 94 
IIST OF TABLES

Page

Table I Computation of Values for Viscosity vs. Temperature Curve . . . . . . . . . . 41 Table II

A Experimental Results - Oil on Tube Side . . . 48 B Experimental Results - 011 on Fin Side . . . 54 Table III Comparison Between Shell and Tube Heat Exchangers With and Without Fins . . . . . 69 
LIST OF FIGURES

Page

Figure 1 Effect of Heat Transmission on Velocity Distribution in Streamline Motion..... 18 Figure 2 MeAdams Correlation.......... $21 \mathrm{~A}$ Figure 3 Schematic Outline of Heat Transfer Unit and Auxiliary Equipment . . . . . . 28 Figure 4 Experimental Heat Exchanger . . . . . . 30 Figure 5 Density vs. Temperature.......... 40 Figure 6 Viscosity vs. Temperature........ . 42 Figure 7 Specific Heat vs. Temperature . . . . . . 43 Figure 8 Thermal Conductivity vs. Temperature . . . 44 Figure 9 Plot of $\left(h_{C}+h_{r}\right)$ vs. Temperature .... 63 Figure 10 Comparison with Sieder and Tate Correlation . 67 Figure 11 Comparison with McAdams Correlation . . . 68 Figure 12 Comparison Between Heat Exchangers ... . 70 
ABSTRACT 
A unit was constructed for the study of film heat transfor coeffloients of a heavy fuel oil in visoous or stroamline flow. The heat exchanger was of the shell and tube type, having extonded longitudinal steol fins welded to the tube. Auxiliary equipment consisted of an ofl pump, oll storage reservoirs, plping, and means for measurement of temperatures and oll flow rates.

The unit was operated both as a fin type heat exchanger with the oil in contact with the finned surfaces, and as a straight tube and shell exchanger with the oil on the tube side. 011 flow rates and temperatures were varied over a wide range.

The data obtained was calculated by the means of existing empirical equations, and the results were compared with those of previous investigators and with the proposed correlations by plotting.

The experimental ly determined film coefficients obtained on the exchanger when operated as a fin type were found to be in agreoment with the best existing correlation. Coefficients determined on the straight tube and shell exchanger were found to be forty per cent higher than the values predicted by this correlation.

A comparison was drawn botween the exchanger as a fin type and as a shell and tube type. The fin type was found to transfor approximately four hundred per cent as much heat per unit length of exchanger as did the stralght shell and tube type. It is belleved that a considerable saving would be effected by the use of a fin type exchanger in any application of heat transfer in which one fluid film definitely controlled the rate of heat transfer. 
INT RODUCTION 
This investigation was undertaken for the following purposes:

1. To determine film coefficients of heat transfer for a heavy fuel oil in viscous flow.

2. To determine film coefficients of the same oil when flowing through a fin-type heat exchanger of tube and shell construction.

3. To compare with existing correlations the data obtained in this investigation.

4. To draw a comparison between heat exchangers of tube and shell construction with and without finned surfaces. The avallable data on heat transfer to flulds in viscous flow has been correlated by Colburn $(1,2)$, Sleder and Tate (3), and McAdams (4); however, no data was avallable which had been obtained under conditions which gave a high ratio of the fluid viscosity at the main stream bulk temperature to the fluid viscosity at the tube wall temperature. Also, in recent investigations, Tepe (5), the data obtained were found to lie somewhat above the correlations of Sieder and Tate (3), and McAdans (4).

In this investigation it was attempted to obtain high values of the ratio of the main stream viscosity to the tube wall viscosity, and of the Graetz (8) number, Wc/kL. The coefficients of heat transfer which were determined using a tube and shell heat exchanger 
with and without finned surfaces ${ }^{2}$ are compared with the theoretical values predicted by the correlations of McAdams, and of sieder and Tate.

A comparison is drawn between a straight tube and shell exchanger and a tube and shell exchanger of the fin type, based on the rate of heat transfer per unit length of exchanger.

$I_{\text {The same exchanger was used in both cases; however, the extended }}$ fin area becomes effective only if used in contact with a fluid having relatively low film heat transfer coefficients. 
HISTORICAI 
A general correlation based on analysis of data on heat transfer to fluids inside round pipes is the Dittus-Boeltor (6) equation:

$$
\frac{\mathrm{hD}}{\mathrm{k}}=0.023\left(\frac{\mathrm{DG})^{0.8}}{\mu}{\left.\frac{(\mathrm{c} \mu}{\mathrm{k}}\right)^{\mathrm{n}}}^{\mathrm{n}}\right.
$$

where $n=0.4$ when the fluid is being heated, and 0.3 when the fiuid is being cooled.

It has been found that, while this equation satisfactorily corrolates data for high values of the Reynolds number, it falls to correlate data on the heating and cooling of hydrocarbon olls below values of the Reynolds number of 7000. Between values of 7000 and the critical value of 2100 the equation of Morris and Whitman (7) applies:

$$
\frac{\mathrm{hD} / \mathrm{k}}{(\mathrm{cm} / \mathrm{k})^{0.4}}=\psi \frac{\mathrm{DG}}{\mathrm{\mu}}
$$

where $\psi$ is a function obtained from a plot of $\left.\frac{h D / k}{(0 \mu / k}\right) 0.4$ vs. $\frac{D G}{\mu}$

Colburn and Hougen (2) presented a fundamental equation for fluids in general flowing vertically at low velocities:

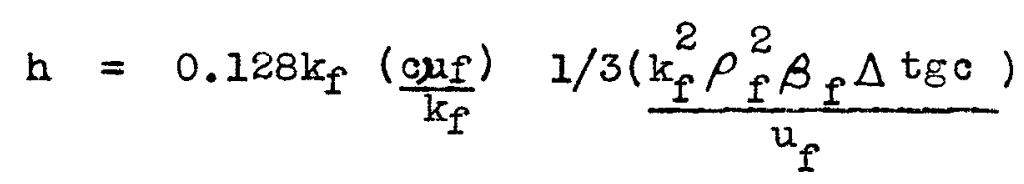

The concept of "thermal turbulent" flow was introduced as the only effective motion of the fluid under conditions of viscous flow. Under such conditions the mean velocity of the fluid is 
held to be unimportant; the controlling motion being that set up by natural convection due to density differenoes caused by the temperature gradient. Since "thermal turbulence" is in reality natural convection, it is controlled by the same variables, and the Grashof number becomes effective. The significance of thermal turbulent flow is questionable when the main stream flow is horizontal, and the movement of the liquid due to convection is at right angles to the forced flow.

McAdams (4) demonstrated the effect of a viscosity gradient set up by the temperature gradient through a cross section of a fluid flowing in streamline motion ${ }^{I}$. He concluded that the effect of this viscosity gradient could not be ignored in any correlation for viscous flow, except under limited conditions of small temperature changes, $\theta$ tc.

Gratz (8) integrated the Fourier-Poisson equation (9) for radial conduction in a moving liquid, using simplifying assumptions $^{2}$ and obtained the relationship:

$$
\frac{t_{2}-t_{1}}{t_{s}-t_{1}}=1-8 \phi\left(n_{1}\right)
$$

where $\phi\left(n_{1}\right)$ represents a convergent infinite series involving the relationship: $\frac{\pi k L}{4 W C}$

$1_{\text {Pages }}\left(\begin{array}{lll}16 \& 17\end{array}\right)$

$2_{\text {Pages }}(17-20)$ 
Introducing the definition of the individual avergge coefficient of heat transfer, the heat balance, and the arithmetic mean temperature difference, the equation of Graetz becomes ${ }^{1}$ :

$$
\frac{h a D}{k}=\frac{2}{\pi}\left(\frac{W c}{k L}\right)\left(\frac{1-8 \phi\left(n_{1}\right)}{1+8 \phi\left(n_{1}\right)}\right)
$$

which represents the theoretical relation based on the parabolic distribution of mass velocity.

Drew and McAdams (10) proposed the empirical equation:

$$
\frac{h_{\mathrm{a}} D}{k}=1.75\left(\frac{W c}{(k L}\right)^{1 / 3}=1.62{\left.\frac{(4 W c}{(\pi k L}\right)^{1 / 3}}^{\frac{4}{k K L}}
$$

which agrees with the theoretical equation of Graetz for values of $\frac{\mathrm{WC}}{\mathrm{kL}}$ greater than 10.2

The experimental data on the heating and cooling of oils and glycerine, flowing in either horizontal or vertioal pipes, run considerably above the Drew-McAdams equation when the fluid is being heated, and considerably below when being cooled. These discrepencies were attributed to the lack of a term to allow for the effect of the radial variation in viscosity.

In developing his method of correlating forced convection heat transfer data and fluid friction Colburn (1) concluded that there is no apparent correlation between heat transfer and fluid friction in the viscous region. However, he proposed a general

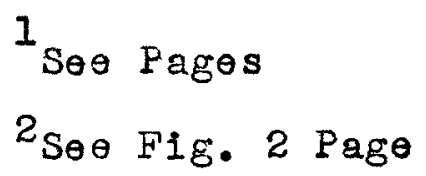


method of correlating heat transfer data which could be used for the entire range of turbulent and viscous flow, based on data obtained using water, air, and petroleum o1l: (2)

$$
\frac{\mathrm{h}_{\mathrm{a}} \mathrm{g}}{\mathrm{k}}=1.62\left(\frac{\left(\mu_{\mathrm{f}}\right)^{1 / 3}\left(1+0.015 \mathrm{Z}^{1 / 3}\right)}{\left(\mu_{\mathrm{f}}\right)}\right) \frac{\left(4 \mathrm{Wc}_{\mathrm{c}}\right)^{1 / 3}}{(\pi \mathrm{kL})}
$$

where $z$ is the Grashof number: $z=\frac{D^{3} \rho f^{2} g \beta \Delta t}{\mu_{f}}$

Sieder and Tate (3) sought a correlation which would be as accurate as that of Colburn, but simpler to use. By employing fluid properties at the main stream temperatures, in contrast to the film temperature properties used by Colburn, they derived the simplified equation:

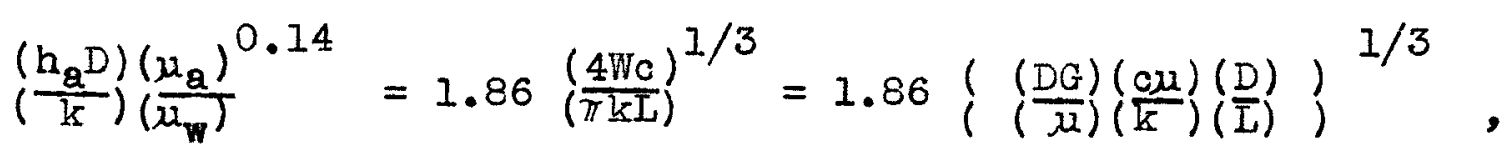

noting that for viscous liquids in tubes of ordinary size the Grashof number is small, and: (4)

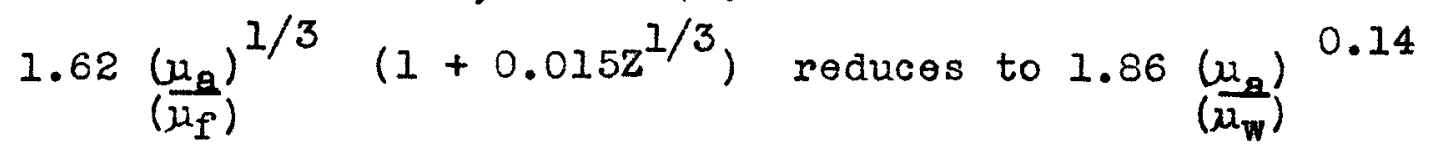

The data correlated by the equation of Sieder and Tate contains few values of the ratio $\mu_{a} / \mu_{w}$ above 10 . It is the purpose of this investigation to obtain higher viscosity ratios

*McAdams (4) states that the constant 1.62 was incorrectly given as 1.5 in reference (1). 
than those obtained heretofore, and to compare this data with the foregoing correlations.

When the thermal resistance on the inside of a metal tube is much lower than that on the outside, as when air is being heated by steam condensing in a pipe, external finned surfaces are of great value in materially increasing the rate of heat transfer per unit length of tube. Considerable data has been published for air and gases flowing outside and normal to banks of finned tubes (4).

No data is avallable, however, on coefficients of heat transfer obtained when longitudinal fins are added to the outer surface of the tube in the conventional shell and tube heat exchanger.

It is the added purpose of this investigation to determine such coefficients and to draw a comparison between the two types of exchangers. 
THEORETICAL 
The basic form of the conduction equation, under steady state conditions, is written as:

$$
\frac{q}{\theta}=\frac{k A \Delta t}{L}=Q
$$

where $q=$ total heat transferred in Btu

$Q=$ total heat transferred por unit time, Btu/hr.

$\theta=$ time in hours

$A=$ heat transfer area in $\mathrm{ft}^{2}$

$L=$ thickness of heat transfer wall in $\mathrm{ft}$.

$\Delta t=$ temperature difference across heat transfer wall, ${ }^{\circ}$. $k=$ thermal conductivity of the material of which the wall is made, Btu/hr. x ft. ${ }^{2} x^{o_{F}}$. fft.

The thermal conductivity $k$ is variable with temperature for any given substance, and this variation is generally linear, corresponding to an equation of the type:

$$
k=a+b t
$$

where $a$ and $b$ are constants and $t$ is the temperature.

Consider a quantity of heat $Q$, passing through a wall of area $A$ and composed of several thicknesses of different materials. Let the thicknesses of the layers be denoted by $I_{1}, L_{2}$, and $I_{3}$, and their thermal conductivities by $k_{1}, k_{2}$, and $k_{3}$ respectively. Let the temperature drop across the whole wall thickness be denoted by $\Delta t$, and across each individual thickness by $\Delta t_{1}, \Delta t_{2}$, and 
$\Delta t_{3}$, respectively. It is then apparent that

$$
\Delta t=\Delta t_{1}+\Delta t_{2}+\Delta t_{3}
$$

Equation (1) can then be written for each of the layers as follows:

$$
\begin{aligned}
& \Delta t_{1}=Q_{1} \times I_{1} / k_{1} A \\
& \Delta t_{2}=Q_{2} \times L_{2} / k_{2} A \\
& \Delta t_{3}=Q_{3} \times L_{3} / k_{3} A
\end{aligned}
$$

Adding (2), (3), and (4):

$$
\begin{aligned}
\Delta t_{1}+\Delta t_{2}+\Delta t_{3} & =Q_{1} I_{1} / k_{1} A+Q_{2} I_{2} / k_{2} A+Q_{3} I_{3} / k_{3} A \\
& =\Delta t
\end{aligned}
$$

Since all the heat which passes through the first layer must pass through the second and third layers also,

$$
\begin{array}{r}
Q_{1}=Q_{2}=Q_{3}=Q, \text { and: } \\
Q=\frac{\Delta t}{\frac{L_{1}}{k_{1} A}+\frac{L_{2}}{k_{2} A}+\frac{L_{3}}{k_{3} A}}
\end{array}
$$

Denoting $L_{1} / k_{1} A, L_{2} / k_{2} A$, and $L_{3} / k_{3} A$ as resistances $R_{1}, R_{2}$ and $R_{3}$ respectively, Eq. (6) becomes:

$$
Q=\frac{\Delta t}{R_{1}+R_{2}+R_{3}}
$$


In the above derivation the area $A$ perpendioular to the direction of the flow of heat remained constant, being a flat surface; however, it is obvious that in the case of heat flow through a curved surface, such as through the wall and lagging of an insulated steam pipe the area perpendicular to the direction of heat flow becomes increasingly larger as the diameter increases. In such a case Eq. (6) becomes:

$$
Q=\frac{\Delta t}{\frac{L_{1}}{k_{1} A_{1}}+\frac{L_{2}}{k_{2} A_{2}}+\frac{L_{3}}{k_{3} A_{3}}}
$$

where $A_{1}, A_{2}$ and $A_{3}$ represent the areas of the varlous thioknesses respectively.

In any case of heat transfer to or from a fluld through a wall there is a thermal resistance to heat flow, and therefore a temperature drop, across a thin film of the fluid adhering to the wall. This resistance may be denoted by $R_{I}=L_{1} / k_{I} A_{I}$; however, due to physical difficulties in the measurement of the thlokness $L_{l}$ and the conductivity $k_{l}$, these variables are combined into the film coefficient:

$$
\mathrm{h}_{1}=\mathrm{k}_{1} / \mathrm{I}_{1}
$$

where $h_{1}$ has the units Btu/hr. $x \mathrm{ft}^{2} \times{ }^{\mathrm{O}} \mathrm{F}$.

Considering a tube and shell heat exchanger, with fluid flowing through the tube and steam condensing outside the tube, Eq. (8) would become:

$$
Q=\frac{\Delta t}{\frac{I}{h_{1} A_{1}}+\frac{L}{\frac{L}{A_{a v}}}+\frac{1}{n_{g} A_{8}}}
$$


where $h_{l}=$ film coefficient of fluid in tube, Btu/hr.x ft. ${ }^{2} \times{ }_{F}$.

$A_{1}=$ inside area of tube, ft. ${ }^{2}$

$L=$ thickness of tube wall, $f t$.

$k=$ thermal conductivity of tube wall, Btu/hr.xft. ${ }^{2}{ }_{X}{ }_{F} / f t$.

$A_{\text {av }}=$ mean wall area

$=$ mean of inner and outer wall areas ${ }^{1}$

$\mathrm{h}_{\mathrm{s}}=$ steam film coefficient, Btu/hr.xft. ${ }^{2} \mathrm{x} \mathrm{o}_{\mathrm{F}}$.

$A_{s}=$ outside area of tube, $f^{2} .^{2}$

Since the values of the film coefficients cannot be conveniently determined directly from experimental data, it is customary to define an overall heat transfer coefficient $U$, on the basis of a definite area. For example, if $A_{1}$ is chosen, Eq. (9) becomes (multiplying numerator and denominator of the right hand side by $\left.A_{1}\right)$ :

$$
Q=\frac{A_{1} \Delta t}{\frac{I}{h_{1}}+\frac{A_{1} L}{A_{a v}}+\frac{A_{1}}{A_{s} h_{s}}}
$$

Defining $U_{1}$ as:

$$
U_{1}=\frac{I}{\frac{I}{h_{1}}+\frac{A_{I} I}{A_{a v^{K}}}+\frac{A_{1}}{A_{g} h_{s}}}
$$

it can be seen that

$$
Q=U_{1} A_{1} \Delta t
$$

which is the general mathematical expression for the flow of heat from one medium to another.

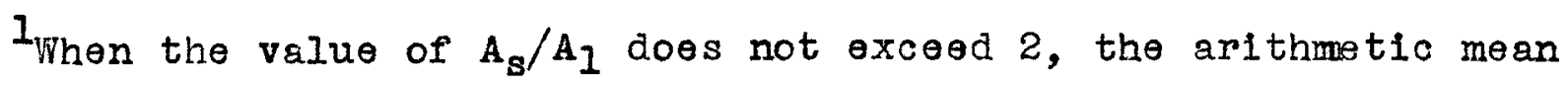
$A_{a v}=\left(A_{I}+A_{s}\right) / 2$ may be used. For values of $A_{S} / A_{I}>2$ use the logarithmic mean:

$$
A_{m}=\frac{A_{s}-A_{I}}{2.3 \log _{\frac{A_{s}}{A_{1}}}}
$$

Mc Adams 
It is clear that other overall coefficients $U_{a v}$, $U_{s}$, etc., could be obtained on the basis of other areas.

In the case of thin walled tubes of large diameter, where the Inner area, outer area, and mean wall area all very nearly equal, it is permissible to use a common value for $A$ as this will introduce a negligible orror into the result. In such a case the resistance equation becomes:

$$
v_{1}=\frac{1}{\frac{1}{h_{1}}+\frac{L}{k}+\frac{1}{h_{s}}}
$$

In any case of heat transfer to a fluid there are several variables which must be included in an oquation which would predict the values of the flim coefficient. These variables aro fluid velocity, its viscosity, thermal conductivity, specific heat, density, pipe diameter, and others in some cases. The only satisfactory means yet found of arranging these variables into useful form is that of dimensional analysis. The following dimensionless groups are of particular importance:

$\begin{array}{ll}\text { Nusselt Number } & \mathrm{hD} / \mathrm{k} \\ \text { Reynolds Number } & \mathrm{DG} / \mathrm{\mu} \\ \text { Prandtl Number } & \mathrm{c} \mu / \mathrm{k} \\ \text { Grashof Number } & \mathrm{D}^{3} \beta p^{2} \triangle \mathrm{tg}_{\mathrm{g}} / \mathrm{\mu}^{2}\end{array}$

where $\mathrm{h}=$ film coefficient of heat transfer, Btu/hr.xft. ${ }^{2}{ }_{\mathrm{F}}$. $D=$ pipe diameter, ft. $\mathrm{k}=$ thermal conductivity of fluid, Btu/hr.xft. ${ }^{2} \mathrm{o}^{\mathrm{F}} \cdot / \mathrm{ft}$. $G=$ mass volocity of fluid, Ib./ft. ${ }^{2}$ xhr. 


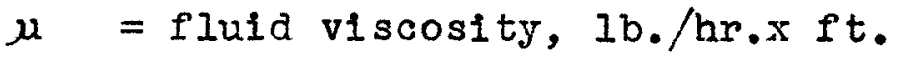

$$
\begin{aligned}
& \mathrm{c}=\text { specific heat of fluid at constant pressure, Btu/lb. } \mathrm{x}^{\mathrm{O}} \mathrm{F} \text {. } \\
& \rho=\text { fluid density, lb. } / \mathrm{ft}^{3} \\
& \beta=\text { coefficient of thermal expansion, } 1 /{ }^{\circ} \mathrm{F} \text {. } \\
& \Delta t=\text { temperature difference, }{ }^{D} \text {. }
\end{aligned}
$$

In the correlation of heat transfer data the above dimensionless groups usually occur in the form:

$$
h D / k=K(D G / \mu)^{a}(\mu / k)^{b}\left(D^{3} \beta \rho^{2} \Delta t g / \mu^{2}\right)^{c}
$$

where $K, a, b$, and $c$ are experimentally determined constants. The correlation may then be established by plotting the experimental data in various ways to obtain the proper relationship betwean the groups.

In the case of a viscous fluid flowing through a long pipe, McAdams (4) demonstrates the effect of a viscosity gradient in the fluid cross section, corresponding to the temperature gradient across the fluid cross section.

When a fluid is flowing at a constant rate through a long pipe under isothermal conditions and in viscous or streamline flow, a parabolic velocity gradient is set up over any cross section, with maximum velocity at the axis and zero velooity at the wall. This condition is shown by curve AA in Fig. I.

If the fluid now enters a section of pipe jacketed by steam condensing at constant temperature, a temperature gradient is set up, the temperature at the wall boing high and that at the axis being low. Since the viscosity of a liquid falls with rise in 
temperature a viscosity gradient is established, with low viscosity at the wall and high viscosity at the axis. As a rosult, the layers of liquid near the wall will flow faster than they did in the unheated section of pipe. Since total flow remains the same some of the liquid from the center of the pipe must flow toward the wall to maintain tho increased velocity of the layers near the wall. The heating of the liquid therefore develops a radial component of the velocity which distorts the parabola to curve $B B$ in Fig. I.

If the liquid were cooled a radial flow in the opposite direction would be devgloped, again distorting the parabola to the shape of curve CC, Fig. I.

If density change is appreciable with temperature other disturbances may occur, although, as pointed out before ${ }^{I}$, these disturbances would probably be negligible in horizontal flow.

It can be concluded from the above presentation that theoretical equations which ignore the distortion of the parabola cannot be expected to op ply except in cases where temperature differences are small or fluid propertios vary only slightly with temperature.

Graetz (8) integrated the Fourier-Polsson equation (9) for radial conduction in a moring liquid, using the following conditions and assumptions:

1. Fluid of specific heat $c$ and thermal conductivity $k$ enters at temperature $t_{1}$, and is heated or cooled without change in phase. 


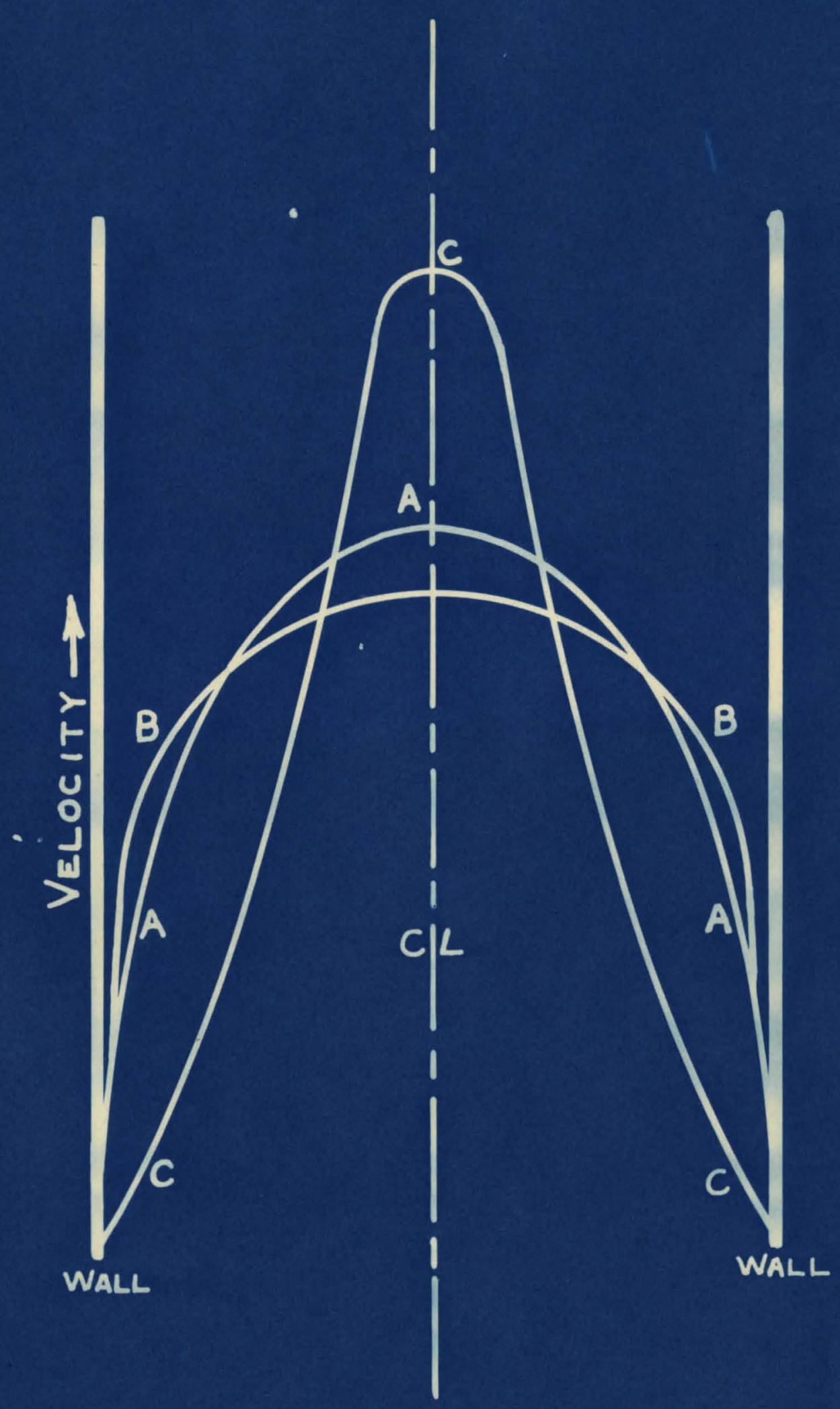

18

Fig. I Effect of Heat Transmission on Velocity Distribution in Streamline Motion 
2. Fluid is flowing inside a pipe having a heated or cooled length $I$, the flow beling at constant mass rate in undistorted laminar motion.

3. Since the flow is assumed to be laminar in character, the distribution of local nass velocity over any cross section is parabollc, with zero wall velocity and maximum axis velocity (ourvo AA in Fig. 1).

4. Heat is assumed to be transferred by radial conduction only, with the thermal conductivity of the fluid remaining uniform. The temperature of the wall surface $t_{s}$ is assumed to be uniform. The relation obtalned by the integration is:

$$
\frac{t_{2}-t_{1}}{t_{s}-t_{1}}=1-8 \phi\left(n_{1}\right)
$$

where $\phi\left(n_{1}\right)=0.10238 \theta-14.6272 n_{1}+0.01220 \theta-89.22 n_{1}$

$$
+0.00237 \theta^{-212 n_{1}}+
$$

and $\mathrm{n}_{1}=\pi \mathrm{kL} / 4 \mathrm{Wc}$

The individual average coefficlent of heat transfer can be defined by:

$$
\begin{aligned}
h_{a} & =A / A \Delta t \\
& =\left(W_{c}\right)\left(t_{2}-t_{1}\right) /(\pi D L)\left(t_{s}-t\right)_{m}
\end{aligned}
$$

Multiplying through by $l / k$ and rearranging terms gives:

$$
h_{a} D / k=1 / \pi \quad\left(W_{0} / k L\right) \frac{\left(t_{2}-t_{1}\right)}{\left(t_{s}-t\right)_{m}}
$$

The average $h$ may be based upon any type of mean temperature 
desired. MoAdams (4) recomends the use of the arithmetic mean of the terminal values for design purposes:

$$
\left(t_{s}-t\right)_{a}=\frac{\left(t_{s}-t_{1}\right)+\left(t_{s}-t_{2}\right)}{2} \quad \pm q
$$

Equations (13), (14), and (15) may be combined as follows:

$$
\begin{aligned}
& t_{2}-t_{I}=\left(t_{s}-t_{1}\right)\left(1-8 \varnothing\left(n_{1}\right)\right) \\
& h_{a} D / k=1 / \pi\left(W_{0} / k L\right) \frac{\left(t_{s}-t_{1}\right)\left(1-8 \phi\left(n_{1}\right)\right.}{\left.\frac{\left.t_{s}-t_{1}\right)+\left(t_{s}-t_{2}\right.}{2}\right)} \\
& =2 / \pi(W o / k L) \frac{\left(t_{s}-t_{1}\right)\left(1-8 \phi\left(n_{1}\right)\right)}{\left(t_{s}-t_{1}\right)+\left(t_{s}-t_{2}\right)} \\
& t_{2}-t_{1}=\left(t_{s}-t_{1}\right)-8 \phi\left(n_{1}\right)\left(t_{s}-t_{1}\right) \\
& t_{2}-\not t_{1}-t_{s}+\not t_{1}=-8 \phi\left(n_{1}\right)\left(t_{s}-t_{1}\right) \\
& \left(t_{s}-t_{2}\right)=8 \varnothing\left(n_{1}\right)\left(t_{s}-t_{1}\right) \\
& \left.h_{a} D / k=2 / \pi(W c / k L) \frac{\left(t_{0}-t_{I}\right)\left(I-8 \phi\left(n_{1}\right)\right)}{\left(t_{s}-t_{I}\right)\left(I+8 \phi\left(n_{I}\right)\right.}\right) \\
& =2 / \pi(W c / k L)\left(\frac{1-8 \phi\left(n_{1}\right)}{1+8 \phi\left(n_{1}\right)}\right)
\end{aligned}
$$

which represents the theoretical relation based on the parabolic distribution of the mass velocity. (curve $A B$ in Fig. 2)

In the special limiting case when the fluid is heated noarly to the constant temperature of the wall, $t_{2}=t_{s}$,

$$
\begin{aligned}
\left(t_{s}-t\right)_{a} & =\left(t_{s}-t_{1}\right) / 2=\left(t_{2}-t_{1}\right) / 2 \\
\left(t_{s}-t_{1}\right) & =\left(t_{2}-t_{1}\right), \text { and } \\
1 & =1-8 \phi\left(n_{1}\right) \\
0 & =-8 \phi\left(n_{1}\right)
\end{aligned}
$$


Then Eq. (16) reduces to:

$$
\mathrm{h}_{\mathrm{a}} \mathrm{D} / \mathrm{k}=2 \mathrm{Wc} / \pi^{\mathrm{kL}}
$$

which is the equation of the asymptote AE in Fig. 2. With constant surface temperature $t_{s}$, no reliable value of $h_{a} K / k$ can Iie above this asymptote.

The emplrical equation proposed by Drew and McAdams corresponds to the theoretical equation (Eq. 16) for values of Wo/kI above $10($ seo Fig. 2):

$$
\mathrm{h}_{\mathrm{Q}} \mathrm{D} / \mathrm{k}=1.75\left(\mathrm{Wc}_{\mathrm{c}} / \mathrm{kL}\right)^{1 / 3}=1.62\left(4 \mathrm{Wc} / \pi^{\mathrm{kL}}\right)^{1 / 3}
$$

The development of the equation of Sieder and Tate (3) is covered in the previous section. ${ }^{1}$

The theory applied to the fin type heat exchanger is similar to that of the straight tube and shell exchanger with the following exceptions:

1. A hydraulic radius, based upon some method of evaluation, must be used in the determination of the equivalent pipe diameter.

2. The temperature of the fins is not equal to the tube wall temperature.

3. There is a large difference between the area of the steam side (inner tube area) and the fluid side (outer bare tube area plus fin area).

There are several methods of evaluating the equivalent diameter. The equivalent diameter is equal to four times the hydraulic radivs, $m$. The hydraulic radius (II) is defined as the 


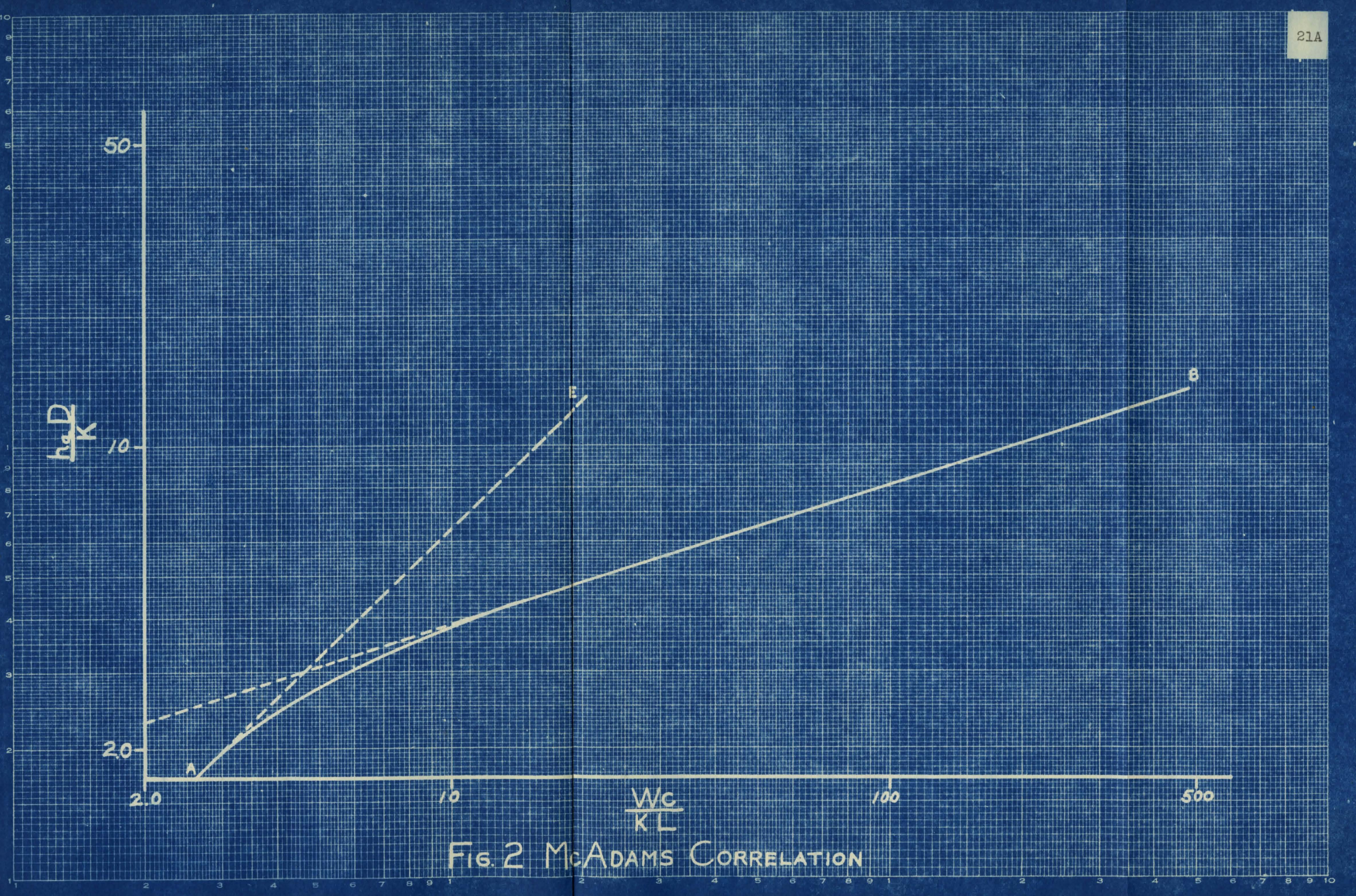


ratio of the cross sectional area to the wetted perimeter.

In this investigation the evaluation of $m$ was made on two soparate bases to determine which value was applicable under the conditions involved:

1. Considering one channel of the annulus alone (cross secional area bounded by the two walls of the annulus and two adjacent fins).

a. Using total wetted perimeter.

b. Using only that portion of the wetted perimeter which transfors heat.

2. Considering the total annulus and ignoring the fin area. a. Using total wetted perimeter.

b. Using only that portion of the wetted perimeter which transfers heat.

McAdams (4) recommends the use of the total wetted perimeter in the calculation of fluid flow problems, and the use of only that portion of the wetted perimeter which transfers heat in the calculation of heat transfer data.

The values of the equivalent diameter obtained from calculation of the hydraulic radius by mothods ( $(a)$ and (Ib) were found to be too low as evidenced by abnormally low values of the Reynolds number $D G / u$, and of the Nusselt number $h_{a} D / k$. Evaluation of the hydraulic radius by mothod ( $2 b$ ) gave abnormally high values of the Reynolds number. The method of (2a) was used in the calculation of the results of this investigation as it gave reasonable values of both $D G / u$ and $h_{a} D / k$.

McAdams (4) presents a method for predicting the temperature 
drop through bar fins from equations obtaingd by the integration of the conduction equation (4).

For finite fins of constant cross section $S$ and perimeter $b$, having surface temperature $t_{x}$, exposed to surroundings at $t_{a}$, a heat balanoe gives:

$$
-k d^{2} t_{x} / d x^{2}=h b d x\left(t_{x}-t_{a}\right)
$$

neglecting radial gradient in temperature. Integration gives:

$$
\text { and } \quad \begin{array}{ll}
(\Delta t)_{x} /(\Delta t)_{0}=\cosh a\left(x_{f}-x\right) / \cosh a x_{f} \\
(\Delta t)_{m} /(\Delta t)_{0}=\tanh a x_{f} / a x_{f}
\end{array}
$$

where cosh and tanh represent the hyperbolic cosines and tangents, respectively:

$$
\cosh y=\left(e^{y}+\theta^{-y}\right) / 2 ; \tanh y=\left(e^{y}-e^{-y}\right) /\left(e^{y}+e^{-y}\right)
$$

and $\theta=2.718$.

The term a is defined as: $a=(\mathrm{hb} / \mathrm{ks})^{0.5}$;

$$
\begin{aligned}
b & =\text { exposed perimeter of the fin } \\
h & =\text { film heat transfer coefficient of the fluid } \\
k & =\text { thermal conductivity of the fin } \\
s & =\text { cross sectional area of the fin } \\
x_{f}= & \text { total length of the fin from its base } \\
x= & \text { distance from base of fin } \\
(\Delta t)_{0}= & \text { temperature difference between the surrounding } \\
& \text { fluid and the base of the fin } \\
(\Delta t)_{x}= & \text { temperature differenoe between the surrounding } \\
& \text { fluid and the fin at distance } x \text { from the base } \\
(\Delta t)_{m}= & \text { mean temperature difference between the } \\
& \text { surrounding fluid and the entire fin. }
\end{aligned}
$$


In this investigation the calculated values of the heat transfor coefficient $h$ are corrected for the drop in temperature along the fins by the above method.

The same heat exchanger was used throughout in obtaining the experimental data presented in this thesis; however, in those experimental runs which were made for a straight tube and shell heat exchanger the flows of steam and oil were interchanged, the steam being placed in contact with the finned surface. Since the controlling thermal resistance was, in all cases, the oll film, the presence of the extended fin area on the steam side had no effect upon the overall heat transfer coefficient, and the exchanger could be considered to be of the stralght tube and shell type. 
EXPERIMENTAL 


\section{APPARATUS}

The experimental apparatus used in this invostigation consisted of a shell and tube fin type heat exchanger, and auxiliary equipment. Two methods of operation were employed, using a heavy grade of industrial fuel oil as the experimental fluid:

1. 011 was passed through the tube and steam was introduced into the shell of the exchanger.

2. 011 was passed through the shell and steam was introduced into the tube of the exchanger.

In each of the methods of operation outlined above, the stoam temperature, and the inlet and outlot oil temperatures wore determined with thermometers, and the rate of oil flow was determined by weighing the amount of oil collected in a tared container over a given timed period.

The pressure of the steam was indicated by a gage, and used as a guide in maintaining constant pressure and therefore constant steam temperature. The pressure was not recorded, and steam quality was not determined, as it was not desired to mun a check heat balance on the exchanger.

Two 550 gallon storage tanks were used as oll reservoirs with provisions for pumping to or from either tank. A rotary gear pump was used to provide oil circulation, and a by-pass across the pump discharge provided control of the rate of oll flow through the exchanger. Quick-opening valves on the return line to the reservoirs permitted instantaneous change of direction of flow from the return line into the tared weighing container at the beginning of a timed period, and from the container to the receiv- 
ing tank at the end of the times period. Times were determined with a one-seoond interval timer.

The arrangement of the apparatus is illustrated in Fig. 3, with the individual parts belng described in detail in the following section. 


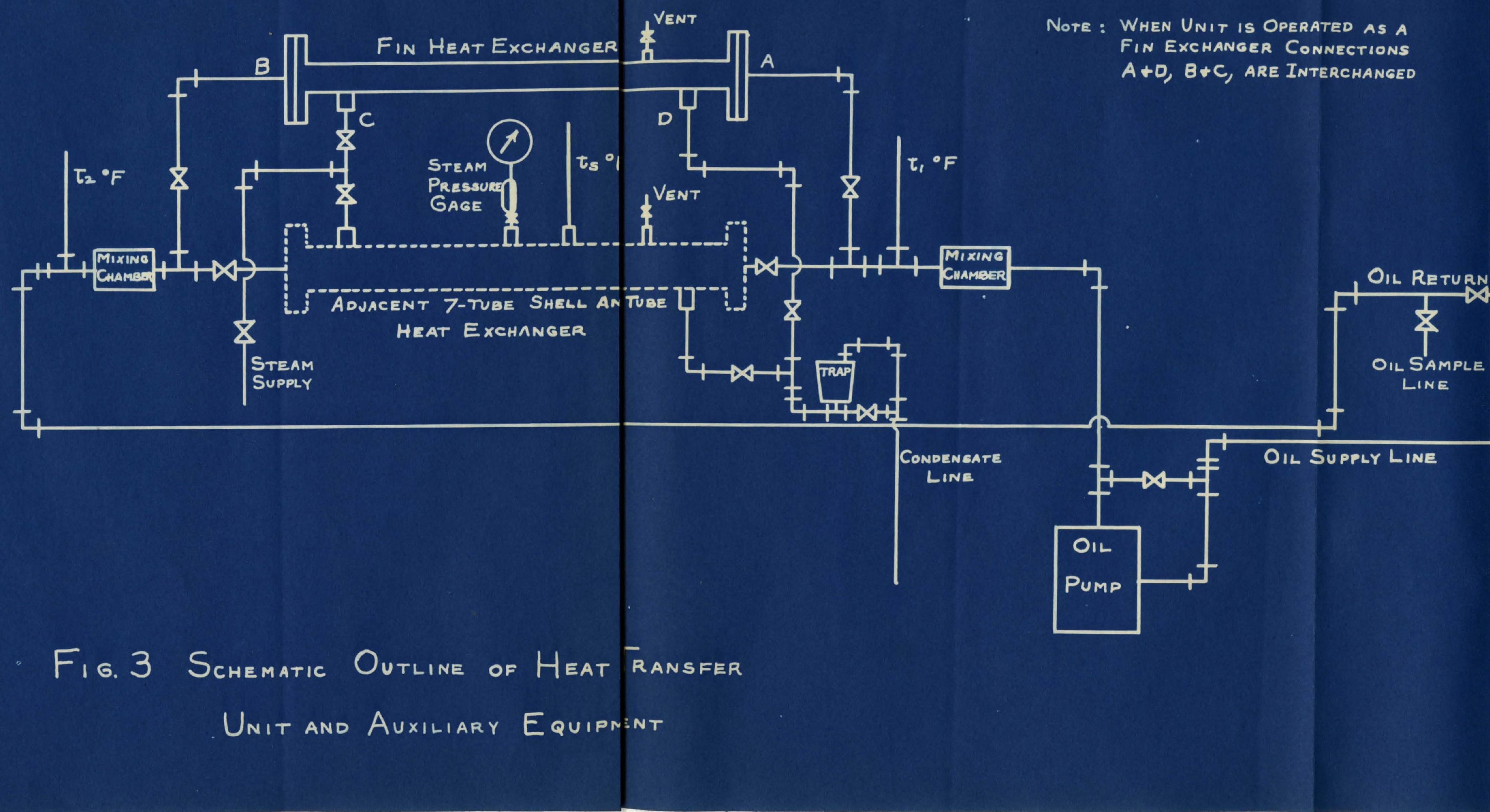


TED AS A INECTIONS

ERCHANGED oil peservoir

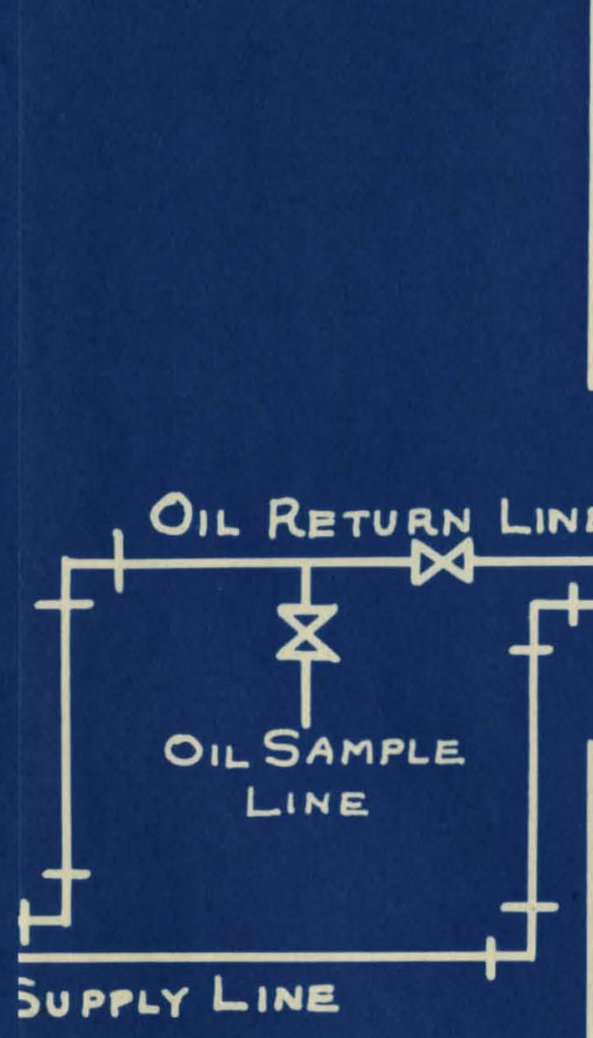

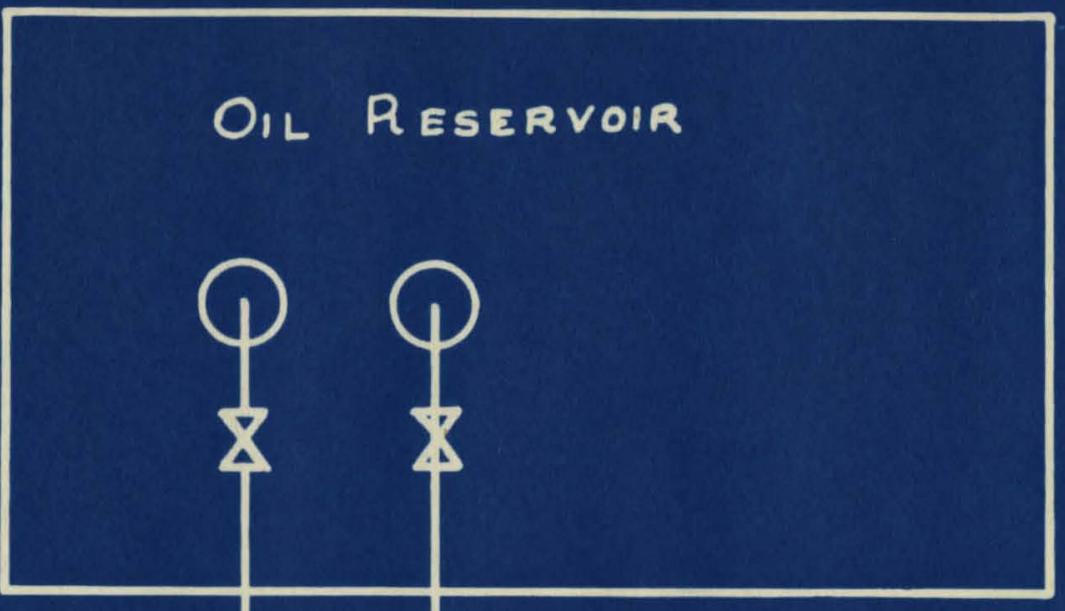

Oil Reservoir 


\section{HEAT EXCHANGER}

The heat exchanger employed in this investigation was supplied by the Henry Vogt Machine Co., of Louisville, Ky. (Fig. 4). It is of the shell and tube type, containing a single \#13 gage sterl tube with an outside diameter of one inch, and a length of approximately seven feot. The tube has twonty longitudinal steel fins spot welded to its outer surface, the fins being one-half inch high and thirteen one-hundradths of an inch in thickness, and approximately six feet in length. The outer extremity of each fin is in contact with the inner wall of the shell.

The shell is constructed of two-inch standard steel pipe, flanged at both ends, and fitted with standard one-inch couplings near aach end at the bottom for introduction of steam and removal of condensate. A three-oighths inch standard coupling welded into the top of the shell near the exit end provides for the removal of air from the shell when starting the period of operation. The shell was not insulated.

There was no provision on the exchanger for the attachment of a steam gage or themometer well for determination of steam temperatures and pressures. These values were measured on the shell of an adjacent seven-tube shell and tube exchanger which was connected in parallel with the steam and oil lines of the exchanger used in this investigation, the seven-tube exchanger being provided with a pressure gage and shell thermometer well. During the operation of the test exchanger the steam and condensate Iines from the parallel exchanger were left open for the 


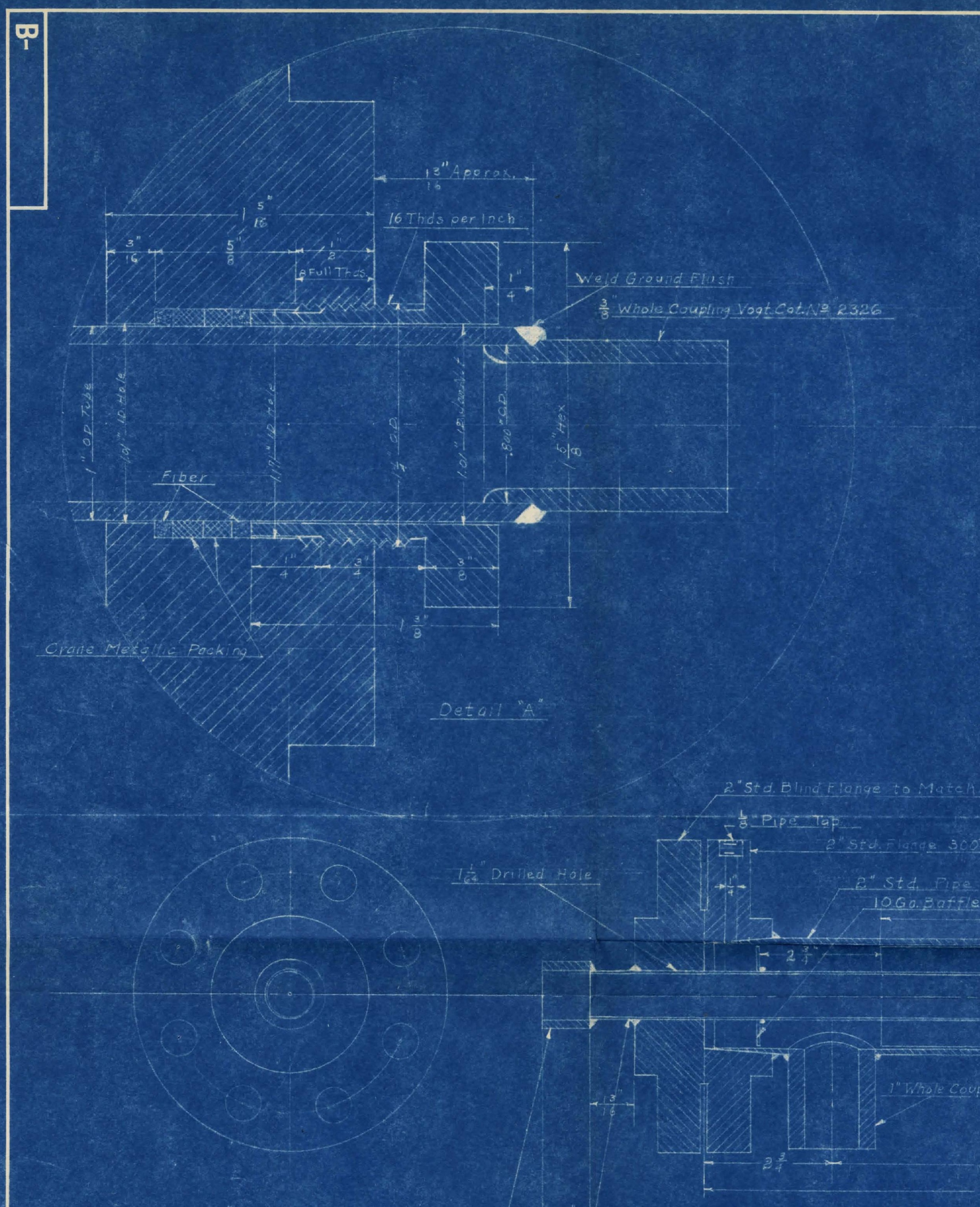

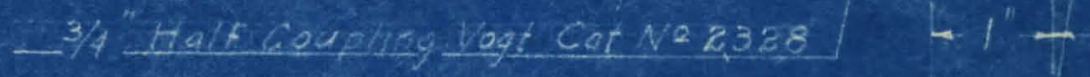

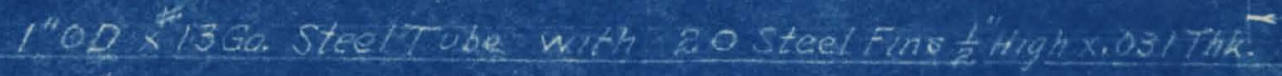

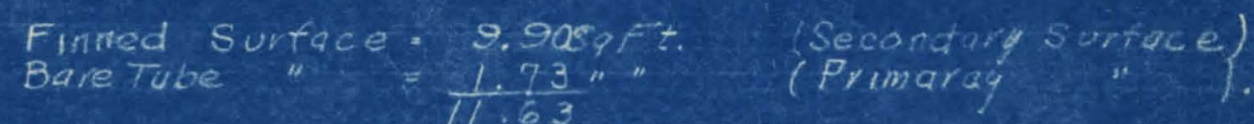




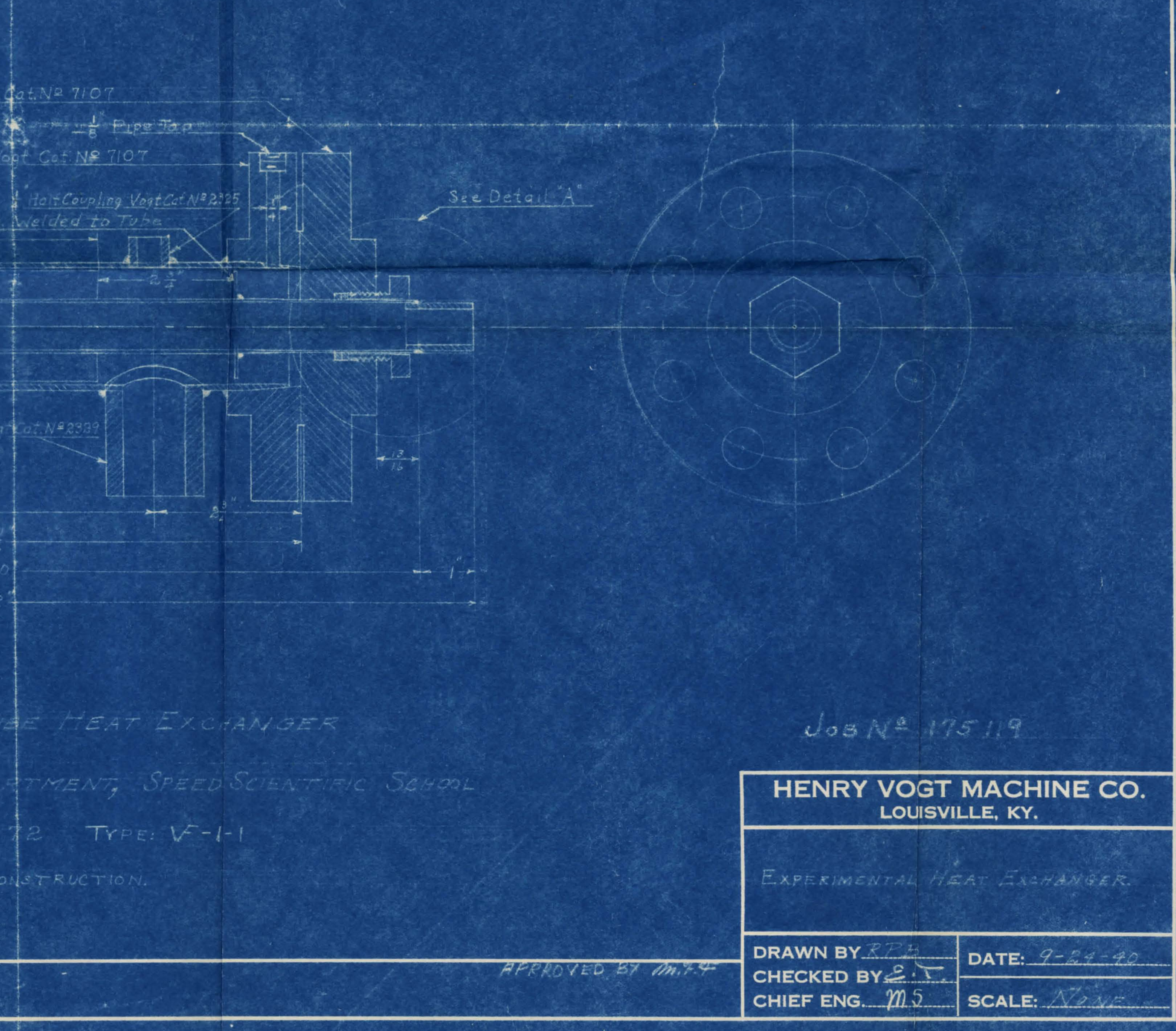


determination of steam temperature and pressure.

In the operation of the unit as a fin type exchanger, the oll and steam Iines were interchanged, allowing the oil to pass through the shell in contact with the finned surfaces of the tube, and the steam to be introduced into the tube at one end, with provisisons for afr venting and condensate removal at the exit end.

Mixing Chambers:

To assure thorough mixing of the oll before determination of the inlet and exit temperatures two cylindrical periorated plate mixing chambers were used. These chambers were constructed and installed by Tepe (5), and a complete description of their construction together with blueprints can be obtained from this thesis. Mixing was effected by turbulence caused by the oll flowing through staggered holes of various sizes in a series of perforated plates.

Thermometer Wells:

Thermometer Wells for the determination of inlet and outlet oll temperaturos were constructed and installed by Tepe (5). Fach well consisted of a one-quarter inch copper tube closed by sweating at one end and of sufficient length to reach into the main stream of the oll without touching the pipe wall. Each of these tubes was brazed into a one-inch standard iron pipe plug. The plugs were screwed into tees at the points at which it was desired to take the oil temperatures. 
Thermometer wells were filled with cottenseed oil. One-fifth degree Fahronheit thermometers were used for the determination of 011 and steam temperatures.

\section{AUXILIARY EQUIPMENT}

Pump:

The pump employod for the circulation of the fuel oil through the heat exchanger is a rotary gear pump, manufactured by the Viking Pump Company, of Cedar Falls, Iowa. It is Type BL, with two-inch suction and discharge openings.

\section{Motor:}

The oil pump was driven by a vestinghouse two hundred and twenty volt three phase five horsepower seventeen hundred and fifty revolutions per minute squirrel cage induction motor. The speed of pump rotation was reduced to one hundred and seventyfive revolutions per minute using a line shaft with intermediate pulleys of twenty-five and five inch diameters. The motor pulley was six inches in diameter and the pump, pulley twelve inches in dianeter.

In order to reduce the pressure drop between the reservolrs and the suction side of the pump, the pump and motor were removed from their existing location on the operating floor and installed in the basement of the laboratory. Since the operating floor is one story above the reservoirs and the basement one-half story below them, this change provided a constant head upon the inlet side of the pump, thus increasing the capacity. 


\section{Reservo1rs:}

The reservolrs consisted of two five hundred and fifty galion underground gasoline storage tanks supplied by the Standard 011 Company of Kentucky. During operation of the heat exchanger oil was pumped from one tank through the beat exchanger into the other tank. The feed and return lines were connected to both tanks so that direction of flow could be reversed at will. 
EXPERINENTAL PROCRDURE 
The following procecure was used in making each experimental run on the heat exchanger:

1. Oil lines were checked

a. To assure correct flow of oil from and to the reservoirs.

b. To make sure that all valves on the discharge side of the pump, including the bypass across the pump discharge and suction lines, were wide open. If the pump were started with the discharge line closed the oil line would be broken as the purn is of the positive displacement type.

2. Steam lines were checked

a. All vents were opened and the condensate drained from the lines.

b. Steam was introduced into the shell of the exchanger and vented to the atmosphere for several minutes to assure removal of air from the shell of the exchanger.

c. Vents were then closed and the steam pressure was adjusted to the desired value.

3. Pump was started and the oil flow rate was adjusted to the desired value by regulation of the pump bypass. Maximum oil flow was obtained by completely closing the bypass.

4. Thermometers were then inserted into the wells for measuring the steam temperature, and the inlet and outlet oil temperatures.

5. The exchanger was allowed to operate for approximately 
one-half hour to attain equilibrium conditions. During this time temperatures and steam pressure were noted.

6. When inlet and outlet oil temperatures, steam temperature and steam pressure became constant, the timed test period was started. Readings of inlet and outlet oil temperatures, and of steam temperatures, were taken at five minute intervals. Steam pressure was maintained at a constant value. Oil rates of flow were determined in most of the runs ten minutes and thirty-five minutes after the start of the run. In a few cases where it became apparent that equilibrium had not been reached at the beginning of the run, the length of the run was extended to one hour's time and a third o1l rate was taken fifty minutes after the starting time.

7. At the completion of the run the thermometers were removed from the wells, the pump was shut down, the steam was shut off, and all vents were opened to the atmosphere. 
RESULTS 
Before the experimental data obtained could be converted to useful form, 1t was necessary to determine the variation of the physical properties of the oil with change in temperature. Information on the variation of these properties was obtained from the thesis of Tepe (5), who determined them experimentally or from reliable sources.

In order to simplify the calculations of the experimental runs made on the heat exchanger, values of the oil viscosity in English units, lb/ft.x hr., were calculated and plotted vs. temperature in F1g. (6). The values in terms of Saybolt seconds wero read from Flf. $5(5)$ at $20^{\circ} \mathrm{F}$. Intervals. Values of the specific gravity of the oll in $\mathrm{gm} . / \mathrm{cc}$. were read at the same temperature intervals from Fig. (5), which was replotted from Fis. 8 (5). Conversion to the English units was effected by the method of Mc Adams (4):

$$
\mu / \rho=A \theta-B / \theta
$$

$$
\begin{aligned}
\text { where } \mu^{\prime} & =\text { viscosity in poises } \\
\rho & =\text { density in gm./0.c. } \\
\theta & =\text { time of efflux in saybolt Seconds } \\
A & =\text { constant } 0.0022 \\
B & =\text { constant } 1.8
\end{aligned}
$$

The value of $\mu^{\prime}$ obtained in poises may be converted to $\mu$, 1b./ft.x hr., by multiplying by 100 to obtain contipoises and by the constant 2.42 to obtain $1 \mathrm{~b} . / \mathrm{ft.x}$ hr. (II) 
The values of the oil viscosity in $1 b . / f t . x$ hr. units were determined as in Table I and plotted vs. temperature in Fig. (6). Values of the specific heats of the oil at various temperatures were replotted in Fig. (7) from Fig. 6 (5).

Values of the thermal conductivity of the oil at various temperatures were replotted in Fig. (8) from Fig. 7 (5). 


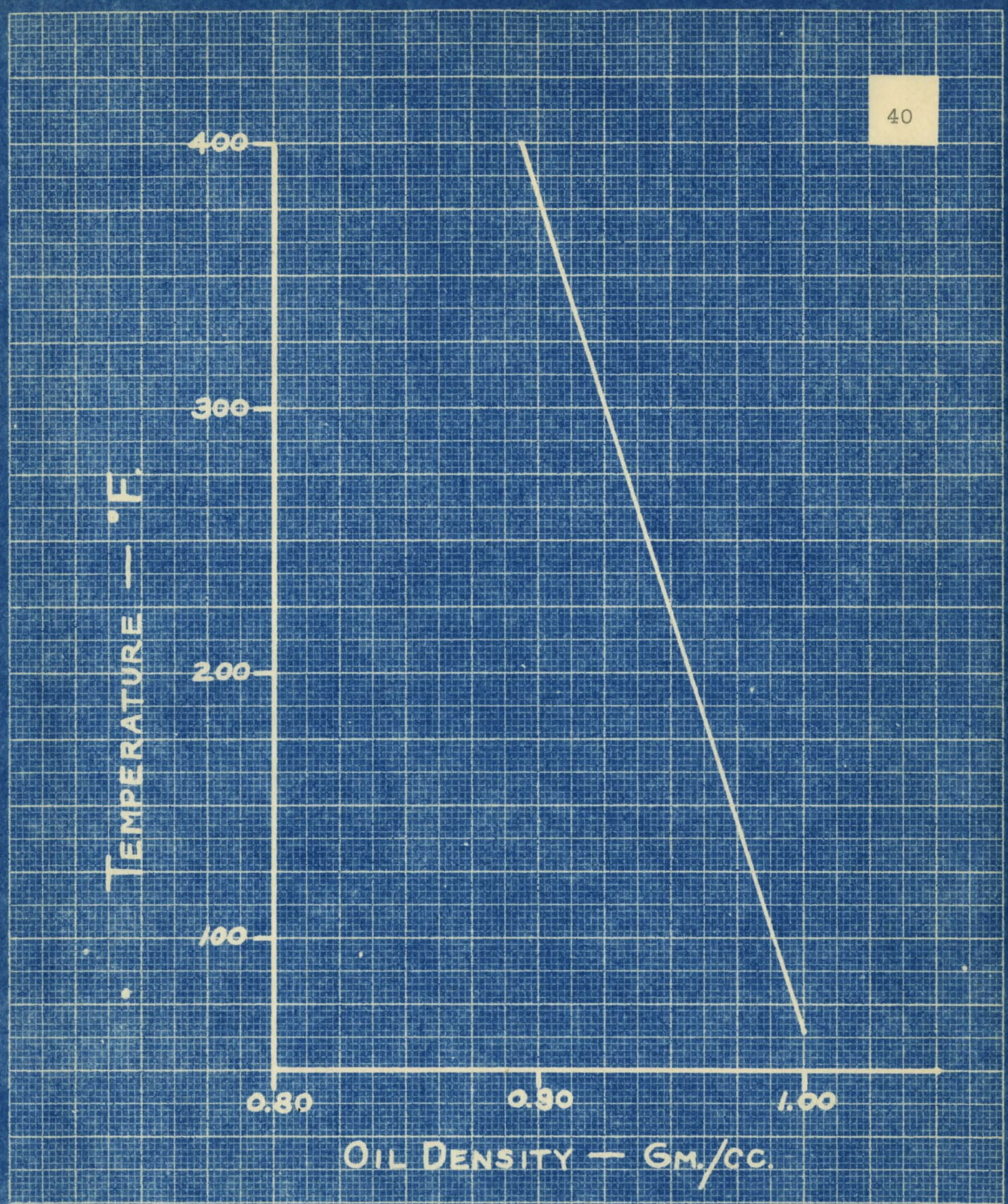

Fia 5 Oil Density vs Temperature. 
TABLE I

COMPUTATION OF VALUES FOR VISCOSITY VS. TEMPERATURE CURVE

As sumed 011

Temp.

$t$

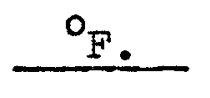

90

110

130

150

170

190

210

230

250

270

290

310
$0 i 1$ Density<smiles>CO</smiles>

$\mathrm{Gm} \cdot / \mathrm{cc}$.

0.9925

0.9860

0.9795

0.9730

0.9675

0.9610

0.9545

0.9480

0.9420

0.9355

0.9300

0.9235
011 V1scosity

011 Viscosity

$\theta$

$$
\mu=(0.00220-1.8 / 0)
$$

Saybolt Seconds

Ib./ft.xhr.

1240

580

310

182

118

84.0

65.0

54.2

47.6

43.0

39.8

37.6
655

304

160.3

91.7

57.2

38.0

26.7

19.7

15.3

11.9

9.52

7.76 


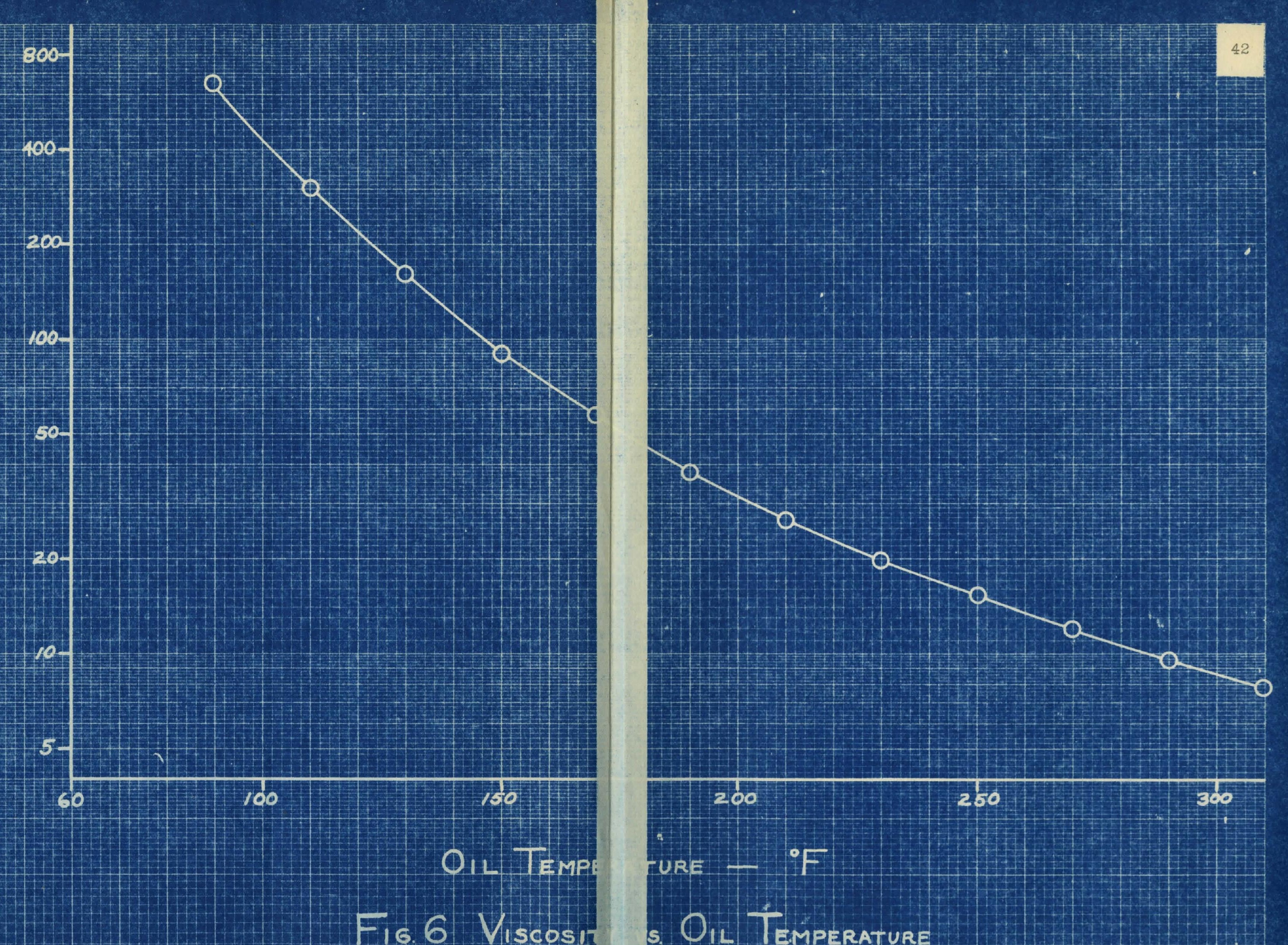




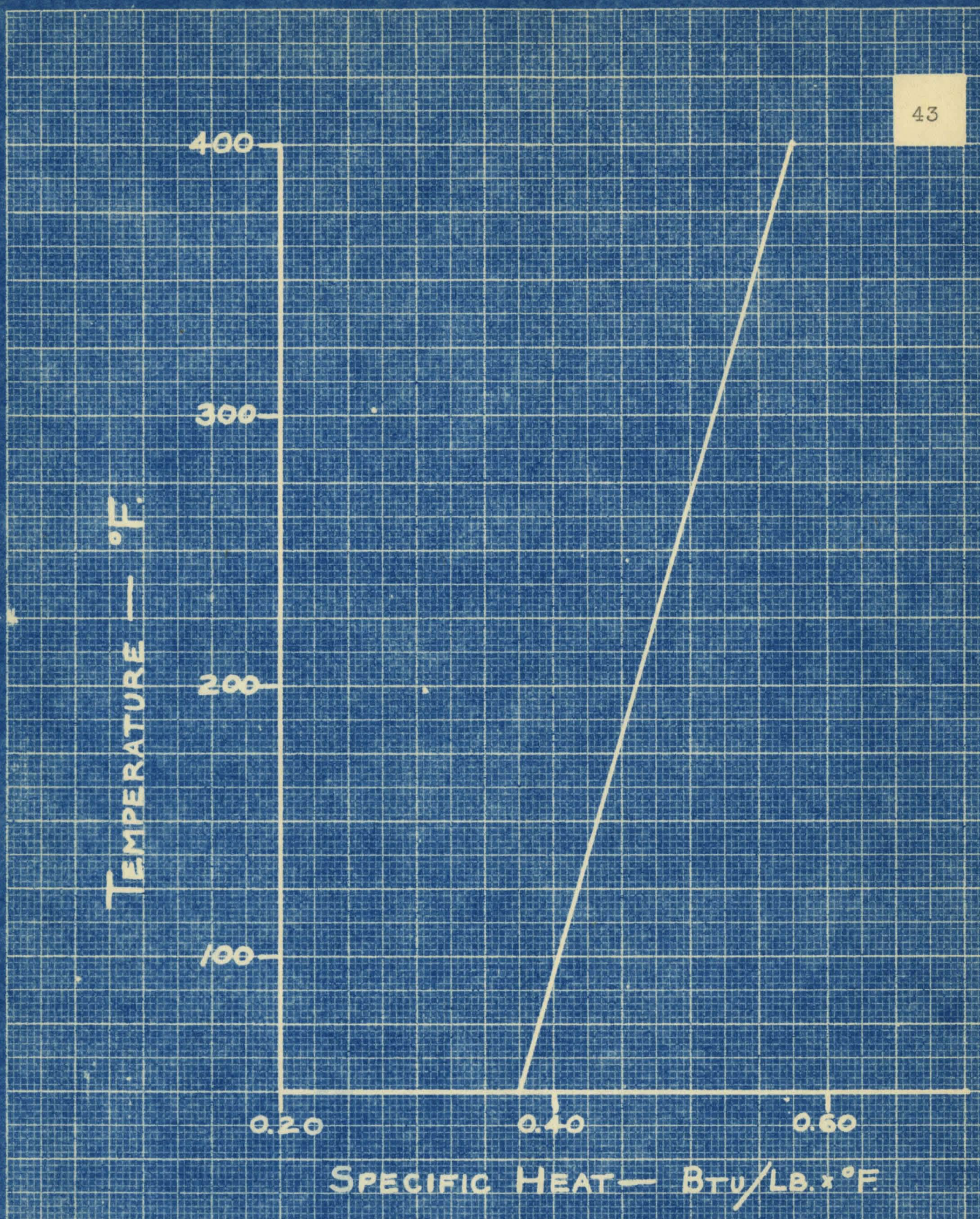

Fig.7 Serecieic Hatat us. Temperature 


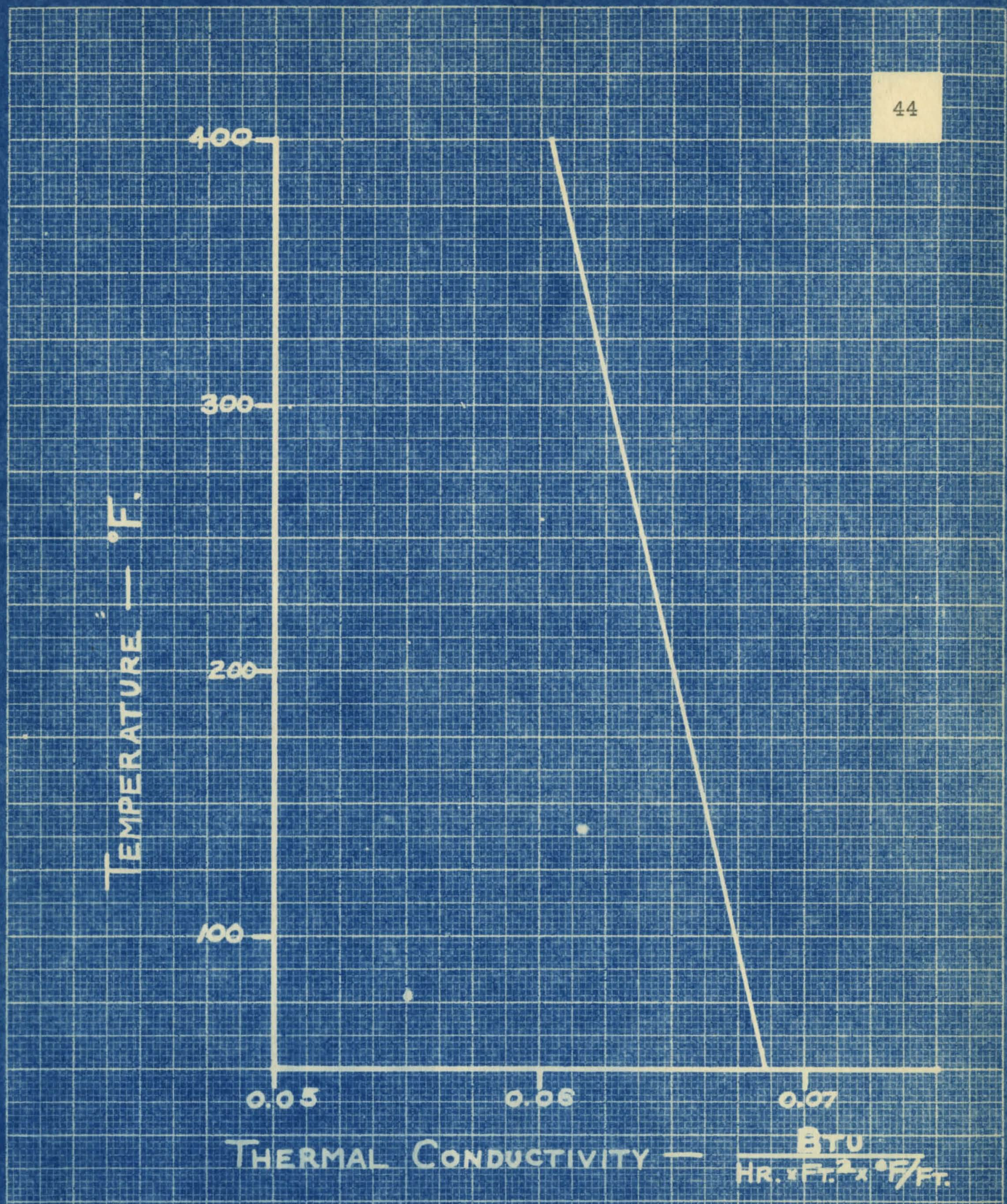

Fig. 8 Thermal Conouctivity va Tmmesature 
The observed and calculated data are tabulated in Table II, together with the indicated mathomatical operations which enable the calculation of each succeding step. Values of the variables and constants used in this table are derived in the Sample Caloulations ${ }^{I}$.

The data for each run are based on the average values of observations made at five minute intervals during the period of each run, during which time operating conditions were kept as nearly constant as possible. As described in the Experimental Procedure ${ }^{2}$ the rate of oll flow was determined either two or three times during each run, depending on the length of the run. In those runs in which it became apparent that equilibriurn had not been reached at the beginning of the run, the unreliable readings taken at the beginning of the run were discarded and the starting period of the run was advanced to a point at which it was apparent that equilibrium had been reached.

As an inspection of Table II will reveal, it is divided into two sections. Table IIA contains data and results for the experimental runs made with the oil on the tube side and the steam on the shell side of the exchanger. Table IIB contains data and results for the experimental runs made with the oil on the shell side, in contact with the fins, and with steam on the tube side.

Since the exchanger was not lagged there was a heat loss from the shell to the surrounding atmosphere due to conduction and convection. This loss was of no significanoe when the exchanger was operated with oil on the tube side and steam in the shell, as all 1 Ipages $(80-91)$

Pages (36) 
heat lost was furnished by the steam in the shell. However, with the exchanger operating with the oil flowing on the shell or fin side the heat lost to the atmosphere was given up by the oil, and this introduced an error into the heat balance which was calculated on the basis of oil temperature rise and rate of flow.

The quantity of heat lost under these conditions was estimated by the method of McAdams (4) and the total heat transferred per hour, Q, was corrected for each run. These corrections were not great, however, ranging from one to five per cent of the total heat transferred per hour. 


\section{TABIE II-A}

EXPERIMENTAI RESUITS - OIL ON TUBE SIDE

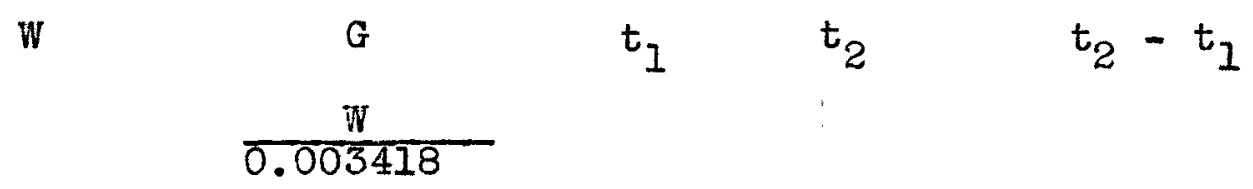

\begin{tabular}{|c|c|c|c|c|c|}
\hline $\begin{array}{l}\text { Run } \\
\text { No. }\end{array}$ & $\mathrm{Ib} . / \mathrm{Hr}$. & Hr. $\mathrm{Lb}$. & ${ }^{o} F$ & ${ }^{{ }^{O}} \mathrm{~F}$ & ${ }^{\circ} F$ \\
\hline $\begin{array}{l}1 \\
2 \\
3 \\
4 \\
5 \\
6 \\
7\end{array}$ & $\begin{array}{r}56.9 \\
90.7 \\
226.0 \\
178.0 \\
416.0 \\
391.5 \\
55.5\end{array}$ & $\begin{array}{r}16,650 \\
26,550 \\
66,150 \\
52,100 \\
121,800 \\
114,600 \\
16,230\end{array}$ & $\begin{array}{l}91.3 \\
89.7 \\
85.3 \\
87.9 \\
80.0 \\
80.0 \\
87.8\end{array}$ & $\begin{array}{l}184.6 \\
181.6 \\
146.2 \\
161.4 \\
141.1 \\
141.0 \\
212.9\end{array}$ & $\begin{array}{r}93.3 \\
91.9 \\
60.0 \\
73.5 \\
61.1 \\
61.0 \\
125.1\end{array}$ \\
\hline
\end{tabular}


TABLE II-A (Cont.)

EXPERTMENTAL RESULTS - OIL ON TUBE SIDE

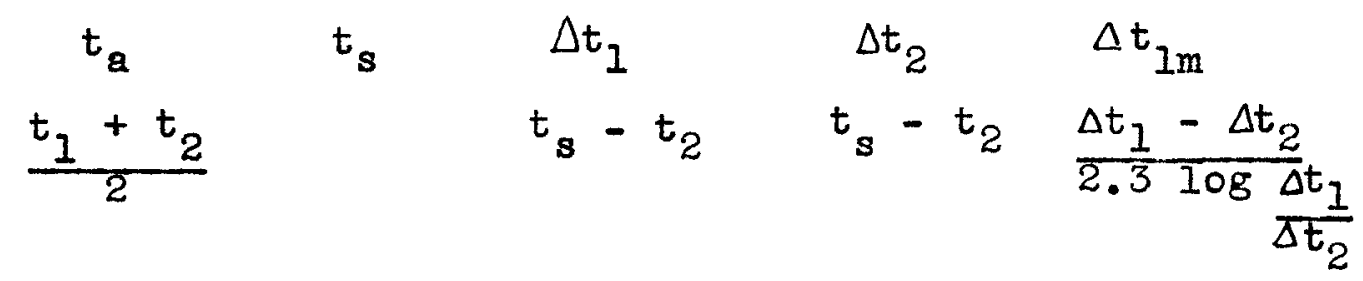

\begin{tabular}{|c|c|c|c|c|c|}
\hline $\begin{array}{l}\text { Run } \\
\text { No. }\end{array}$ & ${ }^{o} F$ & ${ }^{o_{F}}$ & $o_{F}$ & $o_{F}$ & ${ }^{o} F$ \\
\hline $\begin{array}{l}1 \\
2 \\
3 \\
4 \\
5 \\
6 \\
7\end{array}$ & $\begin{array}{l}138.0 \\
136.0 \\
116.0 \\
125.0 \\
110.6 \\
110.5 \\
169.0\end{array}$ & $\begin{array}{l}262.0 \\
272.7 \\
296.8 \\
296.9 \\
301.8 \\
300.1 \\
299.6\end{array}$ & $\begin{array}{l}170.7 \\
183.0 \\
211.5 \\
209.0 \\
221.8 \\
220.1 \\
211.8\end{array}$ & $\begin{array}{r}77.4 \\
91.1 \\
150.6 \\
135.5 \\
160.7 \\
159.1 \\
86.7\end{array}$ & $\begin{array}{l}118.2 \\
131.8 \\
179.4 \\
170.0 \\
190.0 \\
188.8 \\
140.2\end{array}$ \\
\hline
\end{tabular}


TABLE II-A (Cont.)

EXPERIUENTAL RESULTS - OIL ON TLBE SIDE
$\Delta t_{a}$
c
$k$
$\mu_{a}$

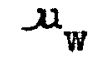
$\frac{\Delta t_{1}+\Delta t_{2}}{2}$
At $t_{a}$
At $t_{a}$
At $t_{a}$
At $t_{s}$

\begin{tabular}{|c|c|c|c|c|c|}
\hline Run & & Btuo & Btu & Lb. & Ib. \\
\hline No. & $F$ & $\overline{\mathrm{Lb} . X} \overline{\mathrm{F}}$ & $\mathrm{Hr} . \mathrm{XFt.x} \mathrm{F}$ & Ft. $x \mathrm{Hr}$. & Ft. $x$ Fr. \\
\hline 1 & 124.0 & 0.4450 & 0.06570 & 128 & 13.1 \\
\hline 2 & 135.7 & 0.4425 & 0.06575 & 136 & 11.7 \\
\hline 3 & 181.0 & 0.4340 & 0.06620 & 250 & 8.95 \\
\hline 4 & 172.2 & 0.4380 & 0.06600 & 187 & 8.95 \\
\hline 5 & 191.3 & 0.4300 & 0.06626 & 307 & 8.45 \\
\hline 6 & 189.6 & 0.4300 & 0.06626 & 307 & 8.60 \\
\hline 7 & 149.3 & 0.4600 & 0.06510 & 58.5 & 8.65 \\
\hline
\end{tabular}


TABLE II-A (Cont.)

EXPERIMENTAL RESULTS - OIL ON TUBE SIDE
$\frac{D G}{\mu_{a}}$
2
$\mathrm{U}_{\mathrm{a}}$
$U_{I m}$
$\frac{1}{U_{a}}$
$\frac{0.0675 G}{\mu_{a}} \quad W c\left(t_{2}-t_{1}\right) \quad \frac{Q}{1.370 \Delta t_{a}} \quad \frac{Q}{1.370 \Delta t_{I m}}$

\begin{tabular}{|c|c|c|c|c|c|}
\hline $\begin{array}{l}\text { Run } \\
\text { No. }\end{array}$ & & Btu/Hr. & 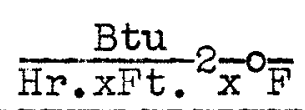 & $\frac{\text { Btu }}{\mathrm{Hr} . \mathrm{xFt} .} 2 \bar{x}^{\mathrm{O}} \overline{\mathrm{F}}$ & $\frac{\mathrm{Hr} \cdot \mathrm{xFt} \cdot{ }^{2} \mathrm{x}^{\mathrm{O}} \mathrm{B}}{\mathrm{Btu}}$ \\
\hline 1 & 8.78 & 2,360 & 13.9 & 14.6 & 0.0719 \\
\hline 2 & 13.17 & 3,685 & 19.9 & 20.4 & 0.0502 \\
\hline 3 & 17.87 & 5,965 & 24.1 & 24.3 & 0.0415 \\
\hline 4 & 18.81 & 5,740 & 24.3 & 24.6 & 0.0411 \\
\hline 5 & 26.8 & 10,930 & 41.7 & 42.0 & 0.0240 \\
\hline 6 & 25.2 & 10,510 & 40.5 & 40.6 & 0.0247 \\
\hline$\sigma$ & 17.73 & 3,200 & 15.7 & 16.6 & 0.0636 \\
\hline
\end{tabular}


TABLE II-A (Cont.)

EXPERINENTAL RESULTS - OIL ON TUBE SIDE

$\frac{1}{U_{I m}}$<smiles>[131In]</smiles>

$\frac{1}{U_{a}}-0.0008$ ha

$$
\begin{gathered}
\frac{I}{h_{I m}} \\
\frac{I}{U_{I m}}-0.0008
\end{gathered}
$$

\begin{tabular}{|c|c|c|c|c|}
\hline $\begin{array}{l}\text { Run } \\
\text { No. }\end{array}$ & $\frac{\mathrm{Hr} \cdot \mathrm{xFt} \cdot{ }^{2} \mathrm{x}_{\mathrm{F}}}{\mathrm{Btu}}$ & $\frac{\mathrm{Hr} \cdot \mathrm{xFt} \cdot{ }^{2} \mathrm{x}^{\mathrm{o}} \mathrm{F}}{\mathrm{Btu}}$ & 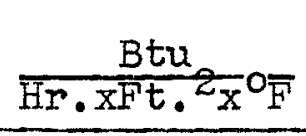 & $\frac{\mathrm{Fr} \cdot \mathrm{xFt} \cdot{ }^{2} \mathrm{x}_{\mathrm{F}}}{\mathrm{Btu}}$ \\
\hline 1 & 0.0685 & 0.0711 & 14.1 & 0.0677 \\
\hline$\alpha$ & 0.0490 & 0.0494 & 20.2 & 0.0482 \\
\hline 3 & 0.0411 & 0.0407 & 24.6 & 0.0403 \\
\hline . & 0.0406 & 0.0403 & 24.8 & 0.0398 \\
\hline 0 & 0.0238 & 0.0232 & 43.1 & 0.0230 \\
\hline 6 & 0.0246 & 0.0239 & 41.8 & 0.0238 \\
\hline 7 & 0.0602 & 0.0628 & 15.9 & 0.0594 \\
\hline
\end{tabular}


TABLP II-A (Cont.)

EXPERIMENTAL RESULTS - OIL ON TUBE SIDE

$$
\begin{aligned}
& h_{I m} \quad \frac{h a D}{k} \quad \frac{h_{1 m} D}{k} \quad \frac{W c}{k L} \quad\left(\frac{4}{\pi} \frac{W c}{k L}\right) \\
& \frac{0.0675 \mathrm{ha}}{\mathrm{k}} \quad \frac{0.0675 \mathrm{~h}_{\mathrm{lm}}}{\mathrm{k}} \quad \frac{\mathrm{Wc}}{6.458 \mathrm{k}}
\end{aligned}
$$

\begin{tabular}{llllrl} 
Run & \multicolumn{1}{l}{ Btu } \\
No. & Hr.xFt. & & & \\
\hline 1 & 14.8 & 14.5 & 15.2 & 59.6 & 75.8 \\
1 & 20.7 & 20.8 & 21.2 & 94.5 & 120.4 \\
2 & 24.8 & 25.1 & 25.3 & 229.0 & 291.5 \\
3 & 25.1 & 25.4 & 25.7 & 183.0 & 232.6 \\
4 & 44.0 & 43.8 & 44.8 & 418.0 & 532.0 \\
5 & 42.0 & 42.6 & 42.8 & 393.0 & 500.0 \\
6 & 16.8 & 16.5 & 17.4 & 60.8 & 77.3
\end{tabular}


TABLE II - (Cont.)

BXPERIMUNTAL RESULTS - OIL ON TUBE SIDI

$$
\begin{array}{rlr}
\left(\frac{4}{\pi} \frac{W c}{k L}\right)^{-1 / 3} & (\mathrm{haD}) & (\mathrm{k}) \\
& \left(\frac{4}{\pi} \frac{W_{c}}{k L}\right)^{-1 / 3}
\end{array}
$$

Run

No.

$\begin{array}{lllr}1 & 0.2362 & 3.422 & 9.77 \\ 2 & 0.2025 & 4.210 & 11.61 \\ 3 & 0.1509 & 3.785 & 27.95 \\ 4 & 0.1626 & 4.130 & 20.90 \\ 5 & 0.1234 & 5.405 & 36.35 \\ 6 & 0.1260 & 5.370 & 35.70 \\ 7 & 0.2347 & 3.875 & 6.76\end{array}$


TABIE II-B

EXPERINENTAL RESULTS - OIL ON FIN SIDE

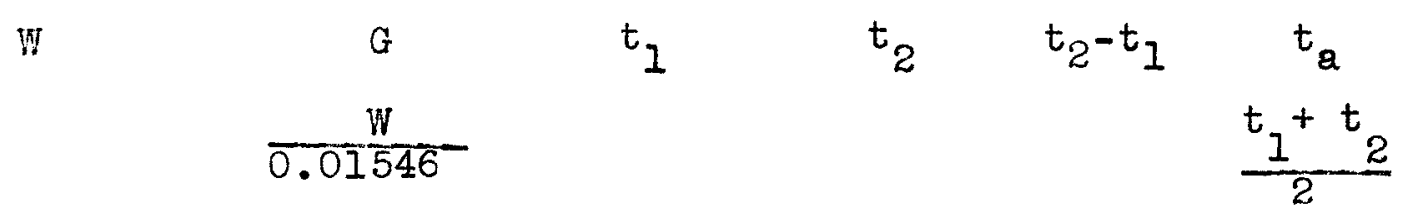

\begin{tabular}{|c|c|c|c|c|c|c|}
\hline $\begin{array}{l}\text { Run } \\
\text { No. }\end{array}$ & $\mathrm{Lb} \cdot / \mathrm{Hr}$. & $\frac{\mathrm{Lb} \cdot-2-}{\mathrm{Hr} \cdot \mathrm{Ft} .}$ & $\mathrm{O}_{\mathrm{F}}$ & ${ }^{O} \mathrm{~F}$ & $o_{F}$ & ${ }^{\circ} \mathrm{F}$ \\
\hline 8 & 216.2 & 14,000 & 93.0 & 198.5 & 105.5 & 145.0 \\
\hline 9 & 1018.0 & 65,850 & 86.0 & 148.7 & 62.7 & 117.8 \\
\hline 10 & 868.0 & 56,150 & 84.3 & 156.4 & 72.1 & 120.8 \\
\hline 11 & 902.0 & 58,400 & 89.6 & 146.6 & 57.0 & 118.1 \\
\hline 12 & 1326.0 & 85,750 & 90.0 & 140.3 & 50.3 & 115.2 \\
\hline 13 & 4220.0 & 273,200 & 119.2 & 139.7 & 20.5 & 129.5 \\
\hline 14 & 1063.0 & 68,800 & 89.9 & 170.9 & 81.0 & 130.4 \\
\hline 15 & 1193.0 & 77,200 & 90.5 & 163.7 & 73.2 & 127.1 \\
\hline 16 & 1792.0 & 116,000 & 96.7 & 150.2 & 53.5 & 123.5 \\
\hline 17 & 840.0 & 54,400 & 86.7 & 157.9 & 71.2 & 122.3 \\
\hline 18 & 980.0 & 63,400 & 88.5 & 173.8 & 85.3 & 131.2 \\
\hline 19 & 337.5 & 21,800 & 83.0 & 216.4 & 138.4 & 149.7 \\
\hline 20 & 341.5 & 22,100 & 82.5 & 171.4 & 88.9 & 127.0 \\
\hline 21 & 351.0 & 22,700 & 82.5 & 190.6 & 108.1 & 136.6 \\
\hline 22 & 373.0 & 24,150 & 82.4 & 203.8 & 121.4 & 143.1 \\
\hline 23 & 396.0 & 25,600 & 83.0 & 218.9 & 135.9 & 160.0 \\
\hline 24 & 394.0 & 25,480 & 83.0 & 223.6 & 140.6 & 153.3 \\
\hline
\end{tabular}


TABLE II-B (Cont.)

EXPERIMENTAL RESULTS - OIL ON FIN SIDE

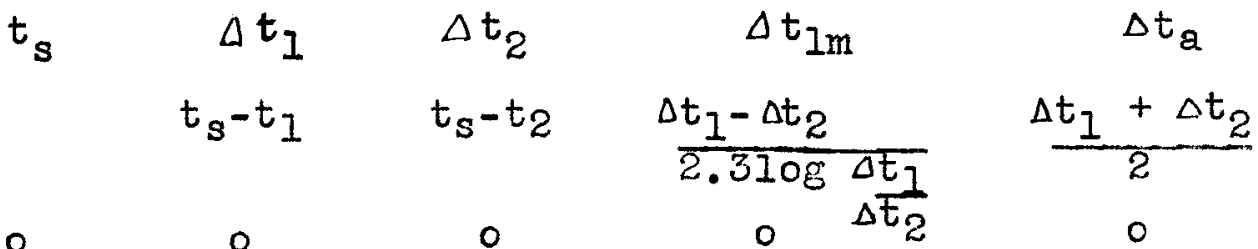

\begin{tabular}{|c|c|c|c|c|c|}
\hline $\begin{array}{l}\text { Run } \\
\text { No. }\end{array}$ & $\begin{array}{l}\circ \\
\mathrm{F}\end{array}$ & ${ }_{\mathrm{O}}^{\mathrm{F}}$ & F & $\begin{array}{l}0 \\
\mathrm{~F}\end{array}$ & F \\
\hline 8 & 261.3 & 168.3 & 62.8 & 107.0 & 115.6 \\
\hline 9 & 258.4 & 172.4 & 109.7 & 138.8 & 141.0 \\
\hline 10 & 262.0 & 177.7 & 105.6 & 138.9 & 141.7 \\
\hline II & 257.6 & 168.0 & 111.0 & 140.3 & 139.5 \\
\hline 12 & 256.7 & 166.7 & 116.4 & 140.7 & 141.6 \\
\hline 13 & 256.9 & 137.7 & 117.2 & 128.6 & 127.4 \\
\hline 14 & 294.5 & 204.6 & 123.6 & 160.3 & 164.1 \\
\hline 15 & 286.1 & 195.6 & 122.4 & 156.7 & 159.0 \\
\hline 16 & 286.8 & 190.1 & 136.6 & 162.1 & 163.4 \\
\hline 17 & 260.8 & 174.1 & 102.9 & 135.2 & 138.5 \\
\hline 18 & 307.3 & 218.8 & 133.5 & 172.7 & 176.2 \\
\hline 19 & 284.3 & 201.3 & 67.9 & 122.9 & 134.6 \\
\hline 20 & 235.2 & 152.7 & 63.8 & 102.0 & 108.3 \\
\hline 21 & 256.1 & 173.6 & 65.5 & 111.1 & 119.6 \\
\hline 22 & 271.8 & 189.4 & 68.0 & 118.8 & 128.7 \\
\hline 23 & 294.7 & 211.7 & 75.8 & 132.2 & 143.8 \\
\hline 24 & 305.3 & 222.3 & 81.7 & 140.6 & 152.0 \\
\hline
\end{tabular}


TABLE II-B (Cont.)

EXPERIMENTAL RESULTS - OIL ON FIN SIDE

$\begin{array}{ccccc}c & k & \mu_{a} & \mu_{w} & \frac{D_{\theta} G}{\mu_{a}}\end{array}$

\begin{tabular}{|c|c|c|c|c|c|}
\hline \multirow{3}{*}{$\begin{array}{l}\text { Run } \\
\text { No. }\end{array}$} & \multirow[b]{2}{*}{ Btuo- } & \multirow[b]{2}{*}{ Btu } & \multirow[b]{2}{*}{$\mathrm{Ib}}$. & \multicolumn{2}{|c|}{$0.0883 \mathrm{G}$} \\
\hline & & & & Lb. & $\mu_{\mathrm{g}}$ \\
\hline & $\mathrm{Lb} \cdot \mathrm{x} \quad \mathrm{F}$ & Fr.x Ft.x F & Et.x $\mathrm{Hr}$. & Ft.x $\mathrm{Fr}$. & \\
\hline 8 & 0.4480 & 0.06560 & 106.0 & 13.3 & 11.62 \\
\hline 9 & 0.4350 & 0.06610 & 235.0 & 13.8 & 24.74 \\
\hline 10 & 0.4360 & 0.06605 & 214.0 & 13.1 & 23.15 \\
\hline 11 & 0.4350 & 0.06610 & 235.0 & 13.8 & 21.90 \\
\hline 12 & 0.4330 & 0.06620 & 260.0 & 14.0 & 29.05 \\
\hline 13 & 0.4410 & 0.06590 & 264.0 & 14.0 & 91.40 \\
\hline 14 & 0.4415 & 0.06585 & 258.0 & 9.15 & 23.55 \\
\hline 15 & 0.4390 & 0.06595 & 177.0 & 10.0 & 38.45 \\
\hline 16 & 0.4380 & 0.06600 & 196.0 & 9.90 & 52.20 \\
\hline 17 & 0.4370 & 0.06610 & 205.0 & 13.4 & 23.40 \\
\hline 18 & 0.4420 & 0.06585 & 156.0 & 7.95 & 35.82 \\
\hline 19 & $0.451 \mathrm{C}$ & 0.06545 & 93.0 & 10.1 & 20.65 \\
\hline 20 & 0.4390 & 0.06595 & 177.0 & 18.4 & 11.02 \\
\hline 21 & 0.4440 & 0.06575 & 132.0 & 14.0 & 15.18 \\
\hline 22 & 0.4470 & 0.06565 & 111.0 & 11.8 & 19.18 \\
\hline 23 & 0.4560 & 0.06530 & 71.5 & 9.10 & 31.60 \\
\hline 24 & 0.4525 & 0.06540 & 84.2 & 8.20 & 26.68 \\
\hline
\end{tabular}


TABLE II-B (Cont.)

EXPERIMENTAL RESULTS - OIL ON FIN SIDE

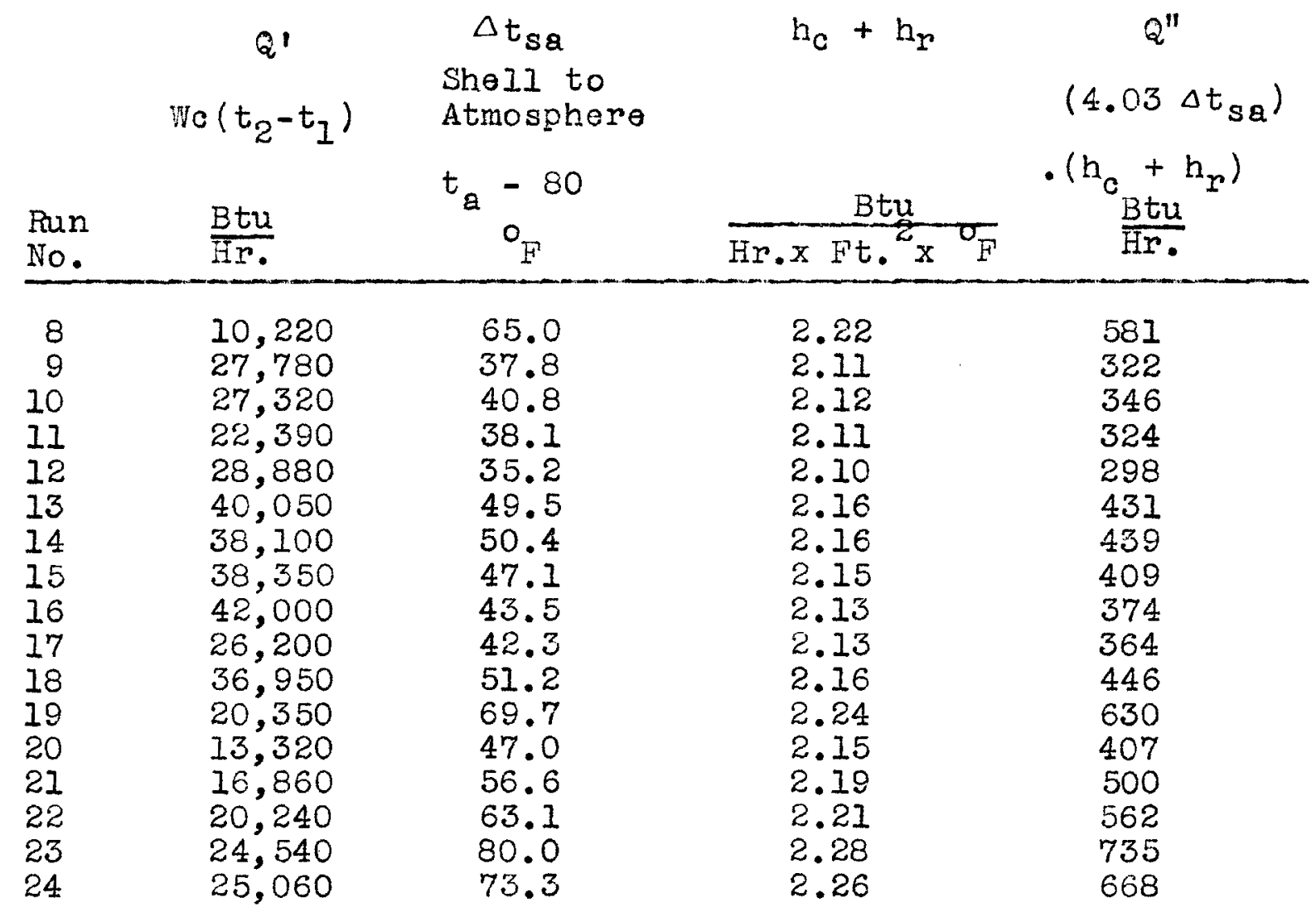


TABLI II-B (Cont.)

EXPERIMENTAL RESULTS - OIL ON FIN SIDE

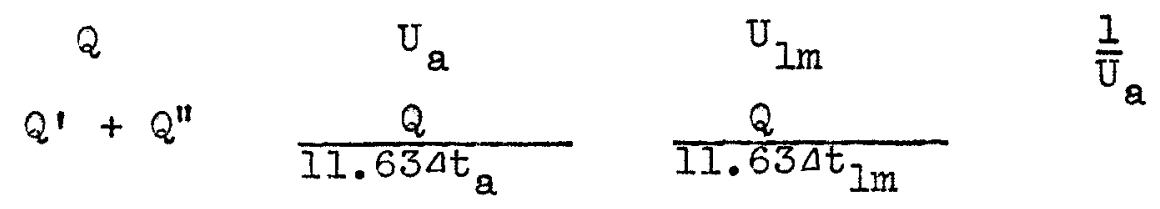

\begin{tabular}{|c|c|c|c|c|}
\hline $\begin{array}{l}\text { Run } \\
\text { No. }\end{array}$ & $\frac{B t u}{\mathrm{H} r}$ & $\frac{\mathrm{Btu}_{2}-\mathrm{O}}{\mathrm{Hr} \times \mathrm{Ft} .} \times \mathrm{F}$ & $\frac{\mathrm{Btu}}{\mathrm{H} r \cdot \mathrm{xF} \cdot{ }^{2}-{ }^{\mathrm{x}} \mathrm{F}}$ & $\frac{\mathrm{Hr} \cdot \mathrm{xFt} \cdot{ }^{2} \mathrm{x}^{\circ} \mathrm{F}}{\mathrm{Btu}}$ \\
\hline 8 & 10,800 & 8,02 & 8.56 & 0.1247 \\
\hline 9 & 28,100 & 17.11 & 17.40 & 0.0584 \\
\hline 10 & 27,670 & 16.80 & 17.12 & 0.0595 \\
\hline II & 22,710 & 13.98 & 13.89 & 0.0715 \\
\hline 12 & 29,180 & 17.70 & 17.80 & 0.0565 \\
\hline 13 & 40,480 & 27.25 & 27.00 & 0.0366 \\
\hline 14 & 38,540 & 20.15 & 20.60 & 0.0496 \\
\hline 15 & 38,760 & 20.92 & 21.22 & 0.0478 \\
\hline 16 & 42,370 & 22.22 & 22.40 & 0.0449 \\
\hline 17 & 26,560 & 16.46 & 16.84 & 0.0607 \\
\hline 18 & 37,400 & 18.21 & 18.61 & 0.0549 \\
\hline 19 & 20,980 & 13.40 & 14.68 & 0.0746 \\
\hline 20 & 13,730 & 10.89 & 11.57 & 0.0918 \\
\hline 21 & 17,360 & 12.47 & 13.40 & 0.0803 \\
\hline 22 & 20,800 & 13.90 & 15.05 & 0.0719 \\
\hline 23 & 25,280 & 15.10 & 16.40 & 0.0661 \\
\hline 24 & 25,730 & 14.52 & 15.71 & 0.0688 \\
\hline
\end{tabular}


TABLE II-B (Cont.)

TIXPERIMENTAL RESULIS - OIL ON FIN SIDE

$\begin{array}{lccc}\stackrel{I}{\bar{U}}_{I m} & \frac{1}{h_{a}} & {\frac{1}{h_{I m}}} & \text { Uncorrected } \\ & \frac{1}{\bar{U}_{a}}-0.0126 & \frac{1}{\bar{U}_{I m}}-0.0126 & \end{array}$

\begin{tabular}{|c|c|c|c|c|}
\hline $\begin{array}{l}\text { Run } \\
\text { No. }\end{array}$ & $\frac{\mathrm{Hr} \cdot \mathrm{xFt} \cdot{ }^{2} \mathrm{X}_{\mathrm{F}}}{\mathrm{Btu}}$ & $\frac{\mathrm{Hr} \cdot \mathrm{xFt} \cdot{ }_{\mathrm{X}} \mathrm{O}_{\mathrm{F}}}{\mathrm{Btu}}$ & $\frac{\mathrm{Hr} \cdot \mathrm{xFt} \cdot{ }^{2} \mathrm{x}^{0} \mathrm{~F}}{\mathrm{Btu}}$ & $\frac{B t u}{H_{r} \cdot x F^{2} .} 2 \bar{x}^{\circ} \bar{F}$ \\
\hline 8 & 0.1168 & 0.1121 & 0.1042 & 8.91 \\
\hline 9 & 0.0575 & 0.0458 & 0.0449 & 21.82 \\
\hline 10 & 0.0584 & 0.0469 & 0.0458 & 21.35 \\
\hline II & 0.0720 & 0.0589 & 0.0594 & 17.00 \\
\hline 12 & 0.0561 & 0.0439 & 0.0435 & 22.80 \\
\hline 13 & 0.0370 & 0.0240 & 0.0244 & 41.60 \\
\hline 14 & 0.0485 & 0.0370 & 0.0359 & 27.00 \\
\hline 15 & 0.0470 & 0.0352 & 0.0344 & 28.40 \\
\hline 16 & 0.0446 & 0.0323 & 0.0320 & 30.95 \\
\hline 17 & 0.0593 & 0.0481 & 0.0467 & 20.80 \\
\hline 18 & 0.0536 & 0.0423 & 0.0410 & 23.62 \\
\hline 19 & 0.0681 & 0.0620 & 0.0555 & 16.10 \\
\hline 20 & 0.0865 & 0.0792 & 0.0739 & 12.62 \\
\hline 21 & 0.0746 & 0.0677 & 0.0620 & 14.77 \\
\hline 22 & 0.0665 & 0.0593 & 0.0539 & 16.87 \\
\hline 23 & 0.0610 & 0.0535 & 0.0484 & 18.68 \\
\hline 24 & 0.0636 & 0.0562 & 0.0570 & 17.78 \\
\hline
\end{tabular}


TABLE II-B (Cont.)

EXPERIMENTAL RESULTS - OIL ON FIN SIDE

$\mathrm{h}_{\mathrm{Im}}$

$\log a x_{f}$

$\operatorname{ax} f$

Uncorrected log ha 0.5 log ha 0.5 log ha

$-1.1763$

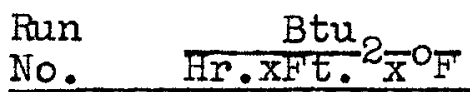

$\begin{array}{rrrrrr}8 & 9.58 & 0.9499 & 0.4750 & -0.7013 & 0.1989 \\ 9 & 22.26 & 1.3389 & 0.6694 & -0.5069 & 0.3113 \\ 10 & 21.82 & 1.3294 & 0.6647 & -0.5116 & 0.3079 \\ 11 & 16.83 & 1.2304 & 0.6152 & -0.5611 & 0.2748 \\ 12 & 23.00 & 1.3579 & 0.6789 & -0.4974 & 0.3181 \\ 13 & 41.00 & 1.6191 & 0.8096 & -0.3667 & 0.4298 \\ 14 & 27.82 & 1.4314 & 0.7157 & -0.4606 & 0.3462 \\ 15 & 29.05 & 1.4533 & 0.7266 & -0.4497 & 0.3550 \\ 16 & 31.20 & 1.4907 & 0.7454 & -0.4309 & 0.3708 \\ 17 & 21.40 & 1.3181 & 0.6590 & -0.5173 & 0.3039 \\ 18 & 24.40 & 1.3733 & 0.6866 & -0.4897 & 0.3238 \\ 19 & 18.00 & 1.2068 & 0.6034 & -0.5729 & 0.2674 \\ 20 & 13.52 & 1.1011 & 0.5506 & -0.6251 & 0.2371 \\ 21 & 16.10 & 1.1694 & 0.5847 & -0.5916 & 0.2561 \\ 22 & 18.56 & 1.2271 & 0.6136 & -0.5627 & 0.2737 \\ 23 & 20.65 & 1.2714 & 0.6357 & -0.5406 & 0.2880 \\ 24 & 19.60 & 1.2500 & 0.6250 & -0.5513 & 0.2809\end{array}$


TABLE II-B (Cont.)

GXPERINENTAL RESULTS - OIL ON FIN SIDE

\begin{tabular}{|c|c|c|c|c|}
\hline \multirow[t]{3}{*}{$\tanh a x_{f}$} & $\frac{(\Delta t)_{m}}{(\Delta t)_{0}}$ & $\begin{array}{l}\text { ha } \\
\text { Corrected }\end{array}$ & $\underset{\text { Corrected }}{\mathrm{h}_{\mathrm{Im}}}$ & $\frac{\text { ha } D_{\theta}}{k}$ \\
\hline & $\tanh a x_{f}$ & ha & $\mathrm{h}_{\mathrm{Im}}$ & $0.0883 \mathrm{hg}$ \\
\hline & $\overline{a x_{f}}$ & $(\Delta t) \mathrm{m} / \mathrm{s}$ & $(\Delta t) \mathrm{m} / \mathrm{u}$ & $\mathrm{k}$ \\
\hline
\end{tabular}

Run

$\begin{array}{rrrrrr}8 & 0.1963 & 0.988 & 9.03 & 9.70 & 12.15 \\ 9 & 0.3016 & 0.969 & 22.55 & 23.00 & 30.10 \\ 10 & 0.2985 & 0.970 & 22.00 & 22.52 & 29.40 \\ 11 & 0.2681 & 0.975 & 17.42 & 17.28 & 23.25 \\ 12 & 0.3078 & 0.967 & 23.60 & 23.80 & 31.45 \\ 13 & 0.4051 & 0.944 & 44.10 & 43.50 & 59.10 \\ 14 & 0.3330 & 0.961 & 28.05 & 29.00 & 37.65 \\ 15 & 0.3408 & 0.960 & 29.60 & 30.25 & 39.60 \\ 16 & 0.3547 & 0.956 & 32.40 & 32.60 & 43.40 \\ 17 & 0.2949 & 0.971 & 21.40 & 22.05 & 28.60 \\ 18 & 0.3129 & 0.967 & 24.12 & 25.22 & 32.80 \\ 19 & 0.2612 & 0.976 & 16.50 & 18.42 & 22.25 \\ 20 & 0.2328 & 0.983 & 12.85 & 13.77 & 17.20 \\ 21 & 0.2506 & 0.979 & 15.08 & 16.44 & 20.24 \\ 22 & 0.2671 & 0.976 & 17.28 & 19.00 & 23.20 \\ 23 & 0.2803 & 0.974 & 19.18 & 21.20 & 25.94 \\ 24 & 0.2737 & 0.974 & 18.27 & 20.12 & 24.65\end{array}$


TABLE II-B (Cont.)

EXPERIMENTAL RESULTS - OIL ON FIN SIDE

$$
\begin{aligned}
& \frac{h_{1 m} D_{e}}{k} \quad \frac{W_{c}}{k L} \quad\left(\frac{\left.4 W_{c}\right)}{\pi k L}\right) \quad\left(\frac{4 W_{c}}{\pi k L}\right)^{-1 / 3}\left(\frac{h a D_{\theta}}{k}\right) \\
& \frac{0.0883 \mathrm{~h}_{\mathrm{lm}}}{\mathrm{k}} \quad \frac{\mathrm{Wc}}{6.458 \mathrm{k}} \\
& \left(\frac{(4 W c}{\pi k I}\right)^{-1 / 3}
\end{aligned}
$$

Run

No.

$\begin{array}{rrrrrrr}8 & 13.05 & 228.4 & 290.5 & 0.1510 & 1.83 & 8.0 \\ 9 & 30.70 & 1037.0 & 1320.0 & 0.0912 & 2.74 & 17.0 \\ 10 & 30.05 & 887.5 & 1130.0 & 0.0960 & 2.82 & 16.3 \\ 11 & 23.05 & 918.5 & 1170.0 & 0.0949 & 2.20 & 17.0 \\ 12 & 31.75 & 1342.0 & 1708.0 & 0.0837 & 2.64 & 18.6 \\ 13 & 58.30 & 4370.0 & 5560.0 & 0.0564 & 3.34 & 18.9 \\ 14 & 38.90 & 1105.0 & 1408.0 & 0.0892 & 3.36 & 28.2 \\ 15 & 40.50 & 1229.0 & 1562.0 & 0.0862 & 3.42 & 17.7 \\ 16 & 43.60 & 1842.0 & 2345.0 & 0.0753 & 3.26 & 19.6 \\ 17 & 29.45 & 860.0 & 1094.0 & 0.0970 & 2.78 & 15.3 \\ 18 & 33.85 & 1018.0 & 1297.0 & 0.0917 & 3.01 & 19.6 \\ 19 & 24.85 & 359.5 & 457.0 & 0.1298 & 2.89 & 9.2 \\ 20 & 18.42 & 351.0 & 446.5 & 0.1308 & 2.25 & 9.6 \\ 21 & 22.08 & 366.5 & 466.0 & 0.1290 & 2.61 & 9.4 \\ 22 & 25.55 & 392.5 & 500.0 & 0.1260 & 2.92 & 9.4 \\ 23 & 28.65 & 428.0 & 545.0 & 0.1225 & 3.18 & 7.9 \\ 24 & 27.16 & 422.0 & 537.0 & 0.1230 & 3.04 & 10.3\end{array}$




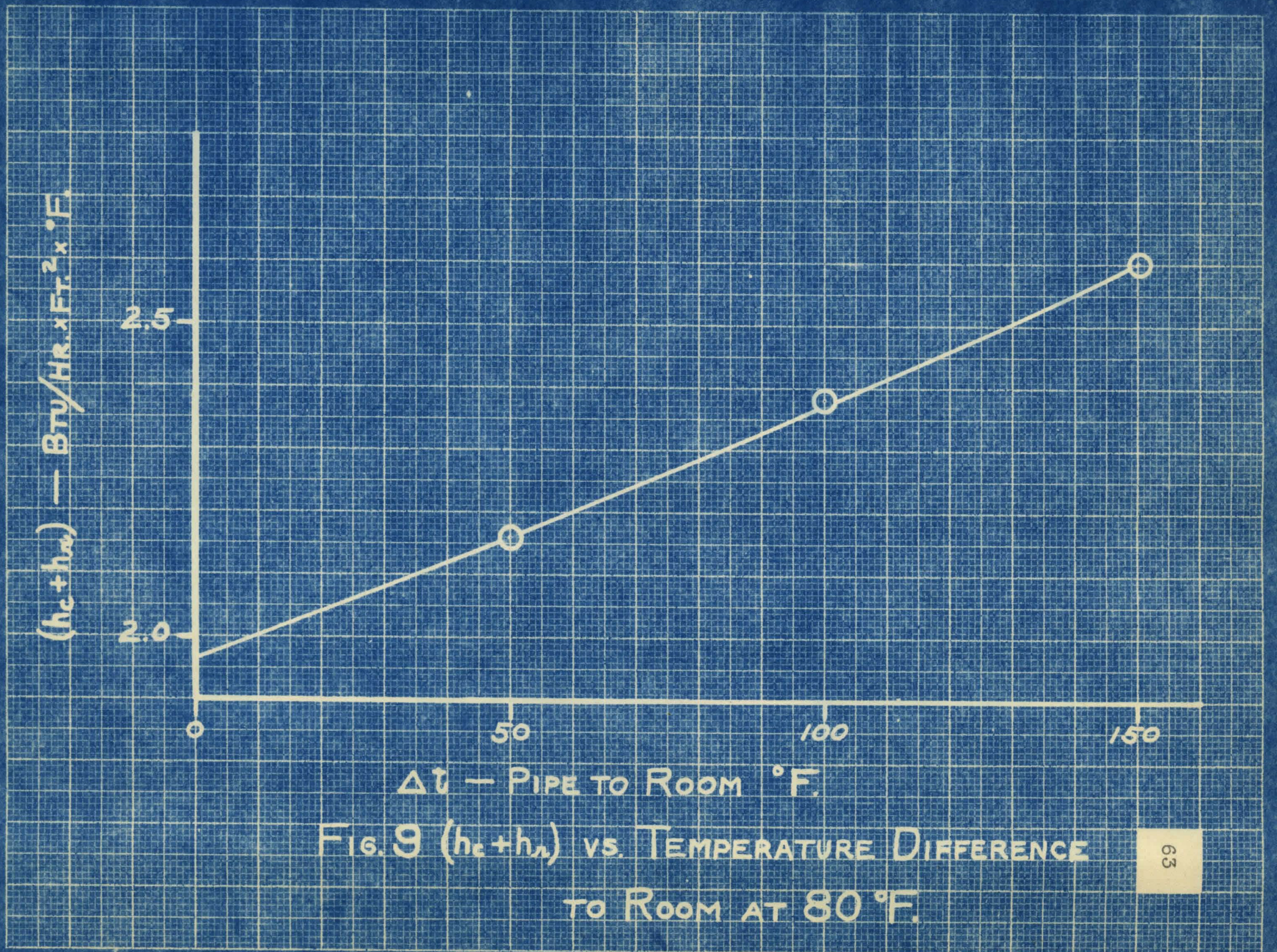


DISCUSSION 
The derived data obtalned as a result of this investigation were plotted according to the existing mothods of correlation, in order to determine whether the empirical equations proposed by these correlations would be substantiated by this data.

In Fig. (10) the proposed correlation of Sieder and Tate (3) is reproduced, and the values obtained in this investigation are plotted on this figure. Most of the data were obtained under conditions such that the values of the ratio $\mu_{a} / \mu_{w}$ were larger than those of the data correlated by Sieder and Tate; the data of the latter including few values of $\mu_{a} / \mu_{w}$ above 10 , while the data derived in this investigation includes values of $\mu_{a} / \mu_{w}$ from 7 to 37 . The data obtained when the heat exchanger was operated with the oll on the tube side was found to lie about forty per cent above the extension of the Sieder and Tate curve, which is in general agreement with the findings of Tepe (5) who reported data approximately fifty-five per cent above the curve.

The data obtained when the heat exchanger was operated with the oll on the fin side was found to lie close to and on both sides of the Sieder and Tate curve, the mean being almost identical with the ourve.

The McAdams (4) correlation is reproduced in Fig. (1I), and the data of this thesis plotted upon it. The data obtained in both methods of operation of the heat exchanger were found to lie considerably above this curve.

In order to draw a comparison between a fin type heat exchanger and a tube and shell exchanger of the same size, values of the total heat transferred per hour per unit length of exchanger, 
Q/I, were tabulated with the corresponding values of the mass velocity, $G$, in Table III. The values of $Q / L$ were then plotted vs. G for each type of exchanger in Fig. (12). 


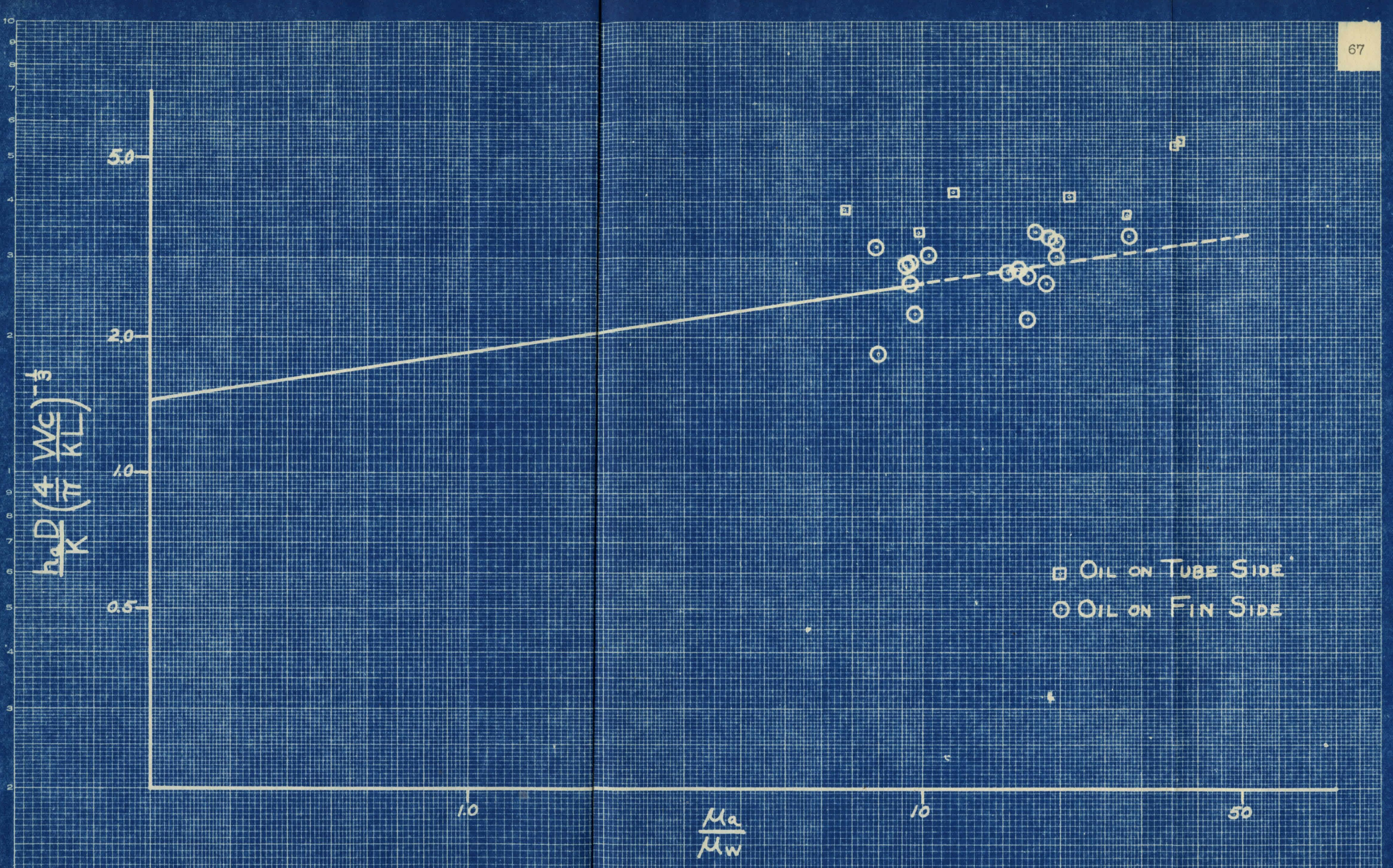

Fig. 10 Comparison with Sieder and Tate Correlation 


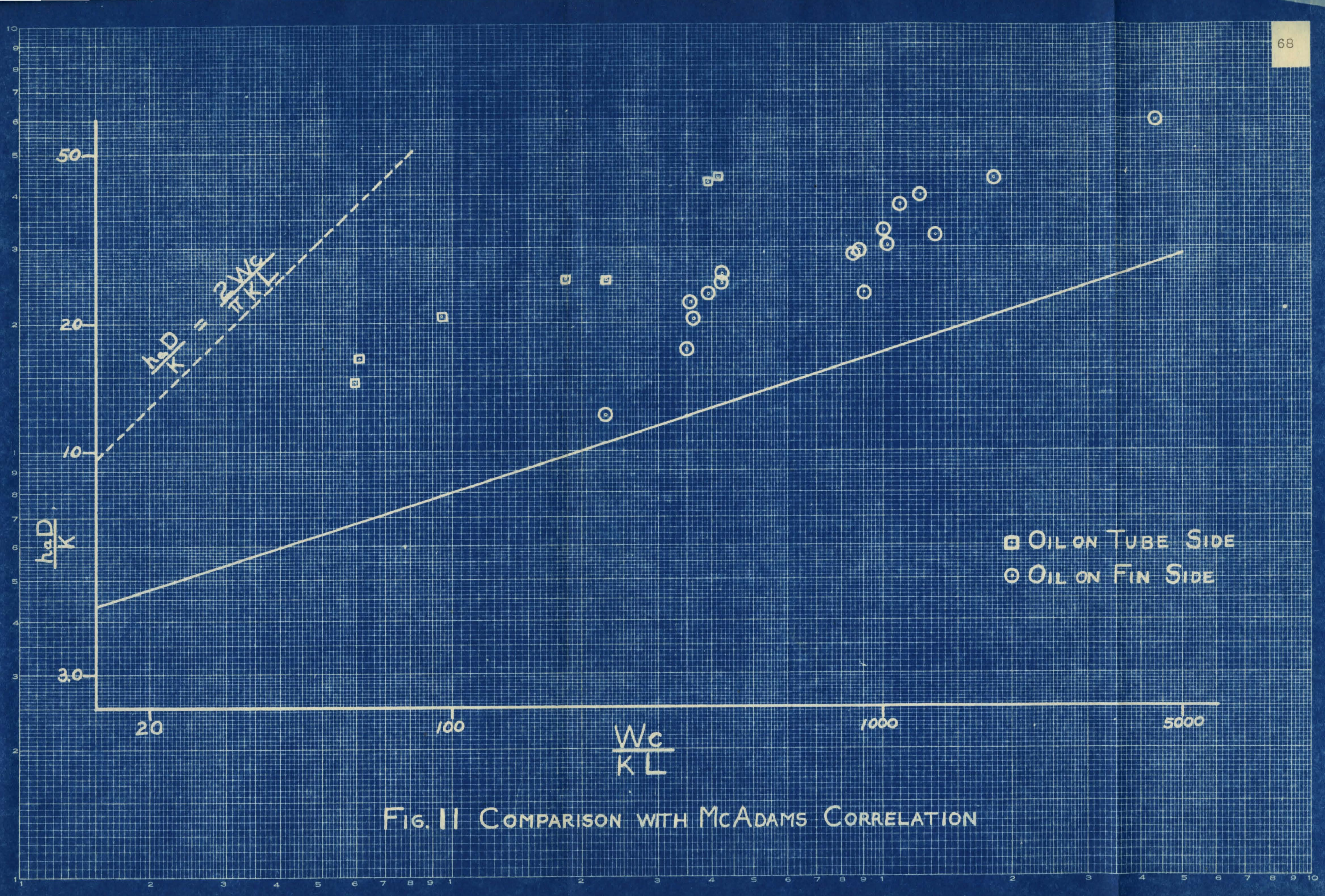


TABLE III

COMPARISON BETWEEN SHEIL AND TUBE HEAT EXCHANGERS WITH AND WITHOUT FINS

Run No.

Q/L

$G$

$$
\text { Q/6. } 458
$$

Btu/hr.x ft.

1b./hr.x ft. 2

$\begin{array}{lr}1 & 365 \\ 2 & 570 \\ 3 & 924 \\ 4 & 888 \\ 5 & 1691 \\ 6 & 1628 \\ 7 & 495 \\ 8 & 1670 \\ 9 & 4350 \\ 10 & 4285 \\ 11 & 3510 \\ 12 & 4510 \\ 13 & 6260 \\ 14 & 5960 \\ 15 & 5995 \\ 16 & 6550 \\ 17 & 4105 \\ 18 & 5790 \\ 19 & 3245 \\ 20 & 2120 \\ 21 & 2684 \\ 22 & 3230 \\ 23 & 3915 \\ 24 & 3980\end{array}$

16,650

26,550

66,150

52,100

121,800

114,600

16,230

14,000

65,850

56,150

58,400

85,750

273,200

68,800

77,200

116,000

54,400

63,400

21,800

22,100

22,700

24,150

25,600

25,480 


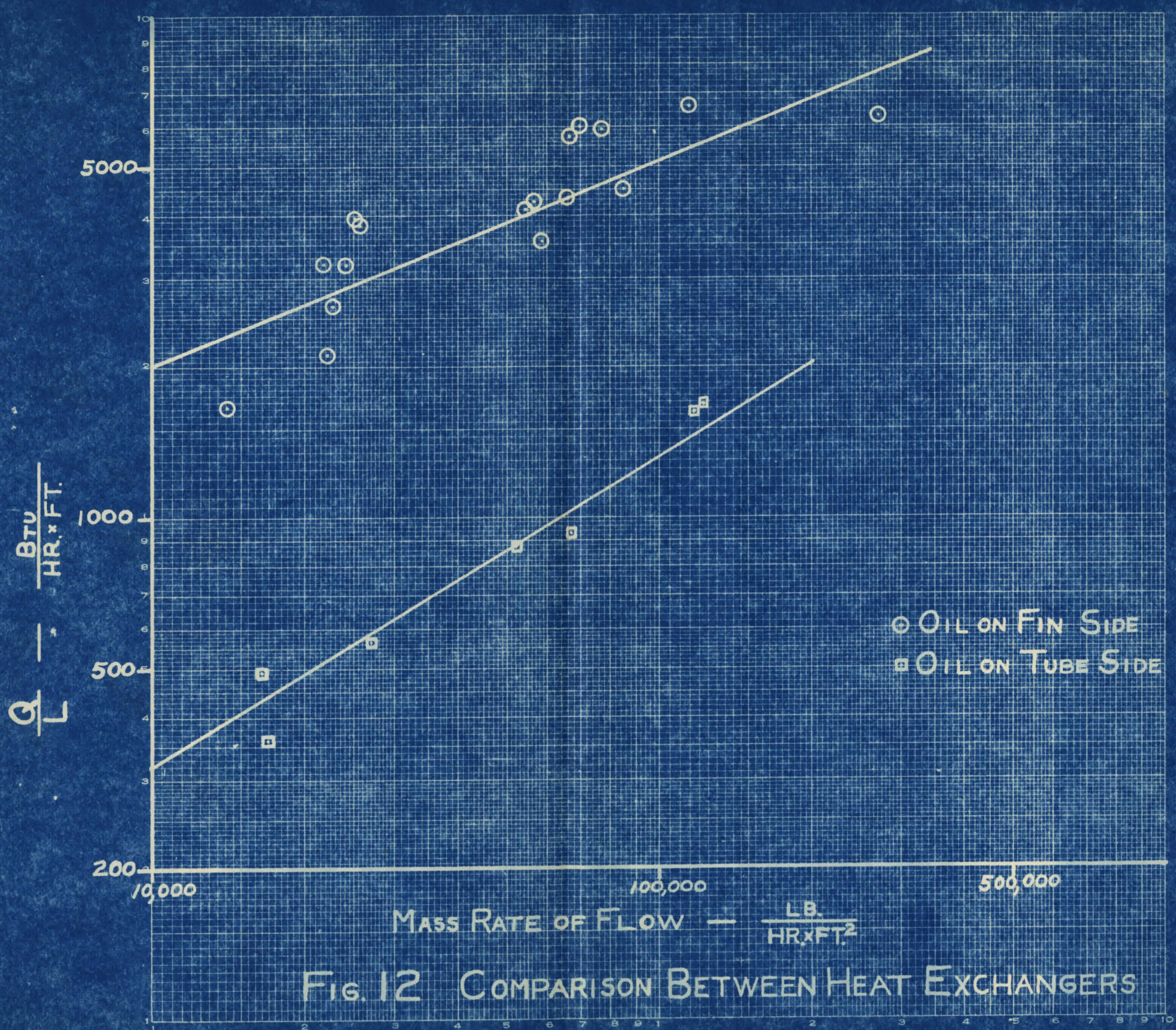


SUMMARY AND CONCLUSIONS 
From the comparisons drawn between the data of this thesis and the correlations of McAdams (4) Fig. (11), and of Sieder and Tate (3) Fig. (10), it can be concluded that the use of a term such as $\mu_{a} / \mu_{w}$, the ratio of the oll viscosities at the bulk temperature and the wall temperature, is necessary to allow for the effect of radial variation in fluid viscosity caused by the temperature gradient through the fluid cross section. This is demonstrated particularly well by the data obtained on the fin type heat exchanger ${ }^{l}$, which is correlated falrly well by the Sieder and Tate method, while falling one hundred per cent above

It should be pointed out here that in order to obtain a correlation of the fin heat exchanger data with previously proposed methods of correlation, it was necessary to modify the previously proposed methods of evaluation of the equivalent pipe diameter. The data correlated by sieder and Tate (3) was obtained on liquids flowing inside tubes, and therefore the problem of evaluating an equivalent diameter did not arise. However, in order to obtain an agreement between this data and the fin heat exchanger data the equivalent diameter had to be evaluated using the total wetted perimeter of the annulus alone, excluding the perimeter of the fins. This is in contrast with the proposed method for heat transfor (4), under which evaluation would be made using only that portion of the wetted perimeter whioh transfors heat. 
the correlation of McAdams, the latter containing no term to allow for the radial variation in viscosity. The data obtained on the straight tube and shell exohanger, while not satisfactorily correlated by olther method, falls closer to the curve of sieder and Tate.

The fallure of the Sieder and Tate correlation for values of the ratio $\mu_{a} / \mu_{w}$ abovo 10 is indicated by the data of Tepe (5) and borne out by the data on the straight tube and shell exchanger which was obtained in this investigation. It is therefore evident that in order to obtain a closer correlation of the data having values of $\mu_{a} / \mu_{w}$ above 10 , an additional factor which takes this into account should be inoluded in the correlation. An examination of the plot of $Q / L$ vs. G (Fig. I2) for the tube and shell exchanger with and without fins shows that the addition of fins permitted an average increase of approximately four hundred per cont in the heat transferred per foot of exchanger length over the same exchanger without fins ${ }^{1}$. Whilo this comparison is not quantitative ${ }^{2}$; considering the results qualitatively it is apparent that in any case of heat transfer where one fluid film is definitely controlling the rate of heat transfer, the use of an exohanger of the fin type would be desirablo in viow of the savings effected in matorial and installation space.

$I_{\text {Se日 }}$ footnote 1 , page 3 .

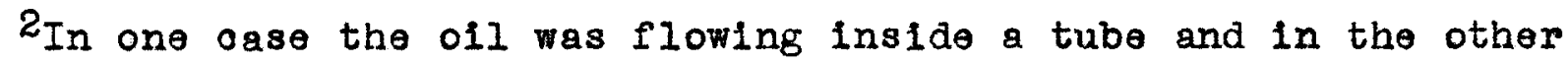
case in the annulus around the tube. To draw a strict oompa rison betweon tube and shell heat exchangers, with and without fins, the oil would have to flow outside the tube in both cases. 
LITERATURE CITED 
1. Colburn, A. P., Trans. A.I.Ch.E., 29, 174 (1933)

2. Colburn, A. P., and O. A. Hougen, Ind. Eng. Chem., 22, 522-534 (1930)

3. Sieder, E. N., and G. E. Tate, Ind. Ing. Chem., 28, 1429-36 (1936)

4. McAdams, W.H., "Heat Transmission" 2nd edition, pp. 7, 12, $186-91,200,232-36,247,407$, New York and London, MoGrawHill Book Company, Inc., 1942

5. Tepe, J.B., Thesis in Chemical Engineering, University of Louisville, 1940

6. Dittus, F.W., and L.I.K. Booltor, Univ. Calif. Pub. in Eng., $2,443(1930)$

7. Morris, F. H., and W.G. Whitman, Ind. Eng. Chem., 20, 234 (1928)

8. Graetz, I., Z. Math. Physik, 25, 316, 375 (1880)

9. Poisson, S.D., "Theorie mathomatique de la chaleur", Bachelier, Paris, 1835

10. Drew, T.B., H.C. Hottel, and W.H. MCAdams, Trans. Am. Inst. Chem. Engrs., 32, 271-305 (1936)

11. Badger, W.L., and W.L. McCabe, "Elements of Chemical Engineering" 2nd edition, pp. 33, 44, 132, New York and London, MoGraw-Hill Books Company, Inc., 1936

12. Perry, J.H., "Chemical Engineers' Handbook" 2nd edition, pp. 110, 874, 949, New York and London, MoGraw-Hill Book Company, Inc., 1941

13. Hedrick, 巴.R., "Logarithmic and Trigonometric Tables" Revised Edition, pp. 116, New York, The Macililan Company, 1937 
APPENDIX 
LIST OF SYMBOLS 
h - film coefficient of heat transfer, Btu/hr.x ft. ${ }^{2} x{ }_{F}$

D - pipe diameter, ft.

$k$ - thermal conductivity, Btu/hr. $x$ ft. ${ }^{2} \mathrm{o}_{\mathrm{F}} / \mathrm{ft}$.

$G$ - mass velocity, 1b./ft. ${ }^{2} \mathrm{x}$ hr.

$\mu$ - viscosity, 1b./ft. $x$ hr.

c - speciflo heat of fluid at constant pressuro, Btu/Ib. $x$ O.

$g$ - acceleration due to gravity, ft./ sec.2

$\Delta t$ - temperature difference, ${ }_{F}$

$t_{I}$ - inlet temperature of fluid, ${ }^{\circ} F$

$t_{2}$ - outlet temperature of fluid, $o_{F}$

$t_{\mathbf{s}}$ - steam temperature, $O_{\mathrm{F}}$

$\beta$ - coefficient of thermal expansion, $1 /{ }^{\circ} \mathrm{F}$

$\rho$ - fluid density, Ib.ft. 3

$I$ - length of tube, ft.

W - weight of fluid flowing per unit time, Ib./hr.

$q$ - total heat transferred, Btu.

Q - total heat transferred per unit timo, Btu/hr.

$\theta$ - time, hrs.

$R$ - thermal resistance, hr. $x f^{2}{ }^{2}{ }^{2} o_{F} /$ Btu

A - heat transfor area, ft. ${ }^{2}$

$U$ - overall coefficient of heat transfer, Btu/hr. $x$ ft. ${ }^{2} x O_{F}$

$x$ - wall thickness and fin length, ft.

a - dimensional factor, l/ft.

$b$ - perimeter of hoat transfor surface, ft.

$S$ - cross sectional area of heat transfer surface, ft. 2 
Subscripts:
a, av., arithmotic moan
$\mathrm{m}, \mathrm{Im}$, logarithmic mean
w, value at the wall or wall temperature
$f$, value at the liquid film or film temperature
$s$, value at the steam temperature; value for sterl
0 , value at the fin base
sa, value from shell to atmosphere
$\theta$, equivalent
1 , inlet value
2, exit value

Nomenolature is that approved by the American Institute of Chemical Engineers. 
SAMPLE CALCULATIONS 
A. OIL ON THE TUBE SIDE

1. Calculation of $G$, mass velocity of the oil, 1b./hr.xft. ${ }^{2}$ outside diameter of tube $=1.0 \mathrm{in}$.

Tube wall is of \#13 BWG gage strel

$\# 13$ gage $=0.095$ in.

Inside diameter of tube

$$
\begin{aligned}
D & =1.0-2(0.095) \\
& =0.810 \mathrm{in} . \\
& =0.0675 \mathrm{ft} .
\end{aligned}
$$

Internal cross sectional area of tube

$$
\begin{aligned}
& =\pi D^{2} / 4 \\
& =(3.14)(0.0675)^{2 / 4} \\
& =0.003418 \mathrm{ft}^{2} \\
G & =w / 0.003418 \mathrm{Ib} . / \mathrm{hr} . \mathrm{xtt} .^{2}
\end{aligned}
$$

2. The calculations of temperatures and temperature differences are self-explanatory in Table IIA.

3. Evaluation of the physical properties of the oll

a. Specific heat, $c$, Btu/lb. $\mathrm{O}_{\mathrm{F}}$, evaluated at the bulk 011 temperaturo $t_{a}$ from Fig. 7 .

b. Thermal conductivity, $k$, Btu/hr. $x \mathrm{ft}^{2}{ }_{\mathrm{X}} \mathrm{o}_{F / f t}$. svaluated at the bulk oil temperature $t_{a}$ from Fig. 8.

c. Oil viscosity at the bulk oil temperature, $\mu_{a}$, evaluated at the bulk oil temperature, $t_{a}$, from Fig. 6 . 
Oil viscosity at the tube wall temperature, $\mu_{s}$, evaluated at the tube wall temperature, $t_{s}$, from Fig. 6.

4. The value of the Reynolds number, $D G / \mu_{Q}$, was calculated using the internal tube diameter $D=0.0675 \mathrm{ft}$.

5. The total heat transferred to the oil, Q, Btu/hr., was calculated from the heat balance on the oil:

$$
Q=W c\left(t_{2}-t_{1}\right)
$$

6. Values of $U$, the overall heat transfer coeffioient, Btu/hr. $x f^{2}{ }^{2} x^{O_{F}}$. were obtained on the basis of both arithmetic and logarithmic mean temperature differences, using the equation for heat transfor:

$$
Q=\mathrm{UA} \Delta t
$$

The heated length of the tube, $L=6.458 \mathrm{ft}$. (Fig. 4)

Internal tube wall area

$$
\begin{aligned}
A & =0.0675 \times 3.14 \times 6.458 \\
& =1.370 \mathrm{ft} .2
\end{aligned}
$$

Then:

$$
\begin{aligned}
U & =Q / A \Delta t \\
& =Q / 1.370 \Delta t
\end{aligned}
$$

7. The values of $h$, the oil film heat transfer coefficient, Btu/hr. $x$ ft. $^{2} \mathrm{x}_{\mathrm{F}}$., wero calculated on the basis of $U_{a}$ and $U_{I m}$ by the resistance equation: 


$$
U=\frac{1}{\frac{1}{h}+\frac{1}{h_{S}}+\frac{T_{w}}{k_{S}}}
$$

$k_{s}=$ thermal conductivity of tube wall

$$
=26 \mathrm{Btu} / \mathrm{hr} . \mathrm{x} \mathrm{ft} .^{2} \mathrm{x}^{\mathrm{o}} \mathrm{F} / \mathrm{ft} \text {. }
$$

$\mathrm{T}_{\mathrm{W}}=$ tube wall thicleness

$$
=0.095 / 12
$$$$
=0.00791 \mathrm{ft} \text {. }
$$

$\mathrm{h}_{\mathrm{s}}=2000 \mathrm{Btu} / \mathrm{hr} \cdot \mathrm{x} \mathrm{ft}^{2} \mathrm{x} \mathrm{o}_{\mathrm{F}}$ (approximate value used for the steam film coefficient when the liquid film coefficiont is relatively smali.)

$$
\begin{aligned}
1 / \mathrm{U} & =1 / \mathrm{h}+1 / \mathrm{h}_{\mathrm{S}}+\mathrm{T}_{\mathrm{w}} / \mathrm{k}_{\mathrm{s}} \\
& =1 / \mathrm{h}+1 / 2000+0.00791 / 26 \\
& =1 / \mathrm{h}+0.0005+0.0003 \\
1 / \mathrm{h} & =1 / \mathrm{J}-0.0008
\end{aligned}
$$

8. The calculation of the dimensionless groups is selfexplanatory in Table IIA. 
B. OIL ON THE FIN SIDE

1. Calculation of $G$, mass volocity of tho oil, Ib./hr. $x$ ft. 2 Outside dianeter of tube $=1.0 \mathrm{in} .=\mathrm{d}_{1}$

Shell of exchanger is 2 in. sta. pipe

$$
\begin{aligned}
\text { Internal diameter of shell } & =2.067 \mathrm{in} . \quad \text { Perry (12) } \\
& =\mathrm{d}_{2}
\end{aligned}
$$

$G$ will be calculated on the basis of the free cross sectional area betwern the shell and the tube. The free area of this annulus is reduced by the total cross sectional area of the fins welded to the outside of tho tubo.

The tube has 20 fins, each 0.5 in. high and 0.031 in. in thickness.

The fins are arranged in pairs, each pair boing connected at the base by a strip of metal 0.031 in. thick, spotwelded to the tube.

The width of this strip is:

$$
\begin{aligned}
\pi \mathrm{d}_{1} / 20-(2 \times 0.031 / 2) & =(\pi)(1) / 20-0.031 \\
& =0.1572-0.031 \\
& =0.1262 \mathrm{in} .
\end{aligned}
$$

The cross sectional area of the fins

$$
\begin{aligned}
& =0.5 \times 0.031 \times 20 \\
& =0.31 \mathrm{in.}^{2}
\end{aligned}
$$


The cross sectional area of the connecting strips

$$
\begin{aligned}
& =0.1262 \times 0.031 \times 10 \\
& =0.039 \mathrm{in.}^{2}
\end{aligned}
$$

Total area to be subtracted from the annular space

$$
\begin{aligned}
& =0.31+0.039 \\
& =0.349 \text { in. }
\end{aligned}
$$

Then, the free area of the annular space

$$
\begin{aligned}
& =\frac{\pi d_{2}^{2 / 4}-\pi d_{1}^{2 / 4}-0.349}{144} \\
& =\frac{(3.14)(2.067)^{2 / 4}-(3.14)(1.0)^{2 / 4}-0.349}{144} \\
& =0.01546 \mathrm{ft.}{ }^{2} \\
& G=\text { w } 0.01546 \mathrm{Ib} . / \mathrm{hr} . x \mathrm{ft} .^{2}
\end{aligned}
$$

2. The calculations of temperatures and tomperature differences are self-explanatory in Table IIB.

3. Evaluation of the physical properties of the oil was made as under A (3).

4. Calculation of the equivalent diameter of the annulus. Since flow occurs in an annular and non-circular cross section an equivalent diameter, $D_{\theta}$, ft., must be calculated. 


$$
\begin{aligned}
& D_{\theta}=4 \mathrm{~m} \\
& m=\frac{\text { area of stream cross section }}{\text { wetted perimeter }}
\end{aligned}
$$

In the calculation of the hydraulic radius $m$, $f t$. , the total wotted perimeter of the annulus, excluding the fins, was used. I

Wetted perimeter

$$
\begin{aligned}
& =\pi(2.067)-(20)(0.031)+(1.0)-(20)(0.031) \\
& =8.40 \mathrm{in} . \\
& =0.70 \mathrm{ft} .
\end{aligned}
$$

Total free cross sectional area of annulus

$$
=0.01546 \mathrm{ft}^{2}
$$

Then:

$$
\begin{aligned}
D_{\theta} & =4 \mathrm{~m} \\
& =(4)(0.01546) / 0.70 \\
& =0.0883 \mathrm{ft} .
\end{aligned}
$$

This value of the equivalent diameter is used in the calculation of the Reynolds number and other dimensionIess groups.

5. The total heat transferred to the oil, Q, Btu/hr. was calculated from the sum of $Q^{\prime}$ and $Q^{\prime \prime}$, where $Q^{\prime}$ was obtained from a heat balance on the ofl:

$$
Q^{\prime}=\operatorname{Wo}_{2}\left(t_{2}-t_{1}\right)
$$

The average temperature of the air surrounding the heat exchanger was $80^{\circ} \mathrm{F}$. The temperature difference from 
the shell to the atmosphere was calculated as the difference

$$
t_{a}-80=\Delta t_{s a}
$$

The heat loss from the shell to the atmosphere, $Q^{\prime \prime}, B t u / h r .$, was calculated by the method of McAdams (4). Values of $h_{c}+h_{r}$, the film coefficients of conduction and radiation respectively, are given for various sizes of bare standard steel pipe, for various values of $\Delta t_{s a}$, the temperature difference between the heated pipe and a room at $80^{\circ} \mathrm{F}$. By interpolation, the values of $h_{C}+h_{I}$ for $50^{\circ} \mathrm{F}$. intervals of $\Delta t_{s a}$ were obtained, and plotted vs. $\Delta t_{s a}$ in Fig. 9.

The area of the shell exposed to the atmosphere and to the oil on the inner side:

$$
\begin{aligned}
& =3.14 \times 2.38 / 12 \times 6.458 \\
& =4.03 \mathrm{ft}^{2}
\end{aligned}
$$

the outside diameter of 2 in. standard pipe belng equal to 2.38 in.

Values of $h_{c}+h_{r}$ were read from Fig. 9 for the calculated value of $\Delta t_{s a}$ for each run, and the heat loss obtained by the relation:

$$
Q^{\prime \prime}=4.03 \times \Delta t_{S Q} \times\left(h_{c}+h_{r}\right)
$$


6. Values of $U$, the overall heat transfer coefficient, Btu/hr. $x$ ft. ${ }^{2} \mathrm{x}$ F., were obtained as under $A$ (6) using the area of the fins + bare tube

$$
\begin{aligned}
A & =9.90+1.73 \\
& =11.63 \mathrm{ft} .2 \\
U & =Q / A \Delta t \\
& =Q / 11.63 \Delta t
\end{aligned}
$$

7. The values of $h$, the oil film hat transfer coefficient, Btu/hr. $x$ ft. ${ }^{2} x \mathrm{o}_{\mathrm{F}}$, were calculated on the basis of $U_{a}$ and $U_{I m}$ by the resistance equation:

$$
1 / \mathrm{h}=1 / U-A / h_{s} A_{S}-x_{W} A / k_{s} A_{W}
$$

where $A=$ heat transfer area on oil or fin side

$$
=11.63 \mathrm{ft} .^{2}
$$

$A_{S}=$ heat transfer area on steam or tube side

$=1.370 \mathrm{ft} .^{2}$

$A_{W}=$ arithmetic mean of the outer and inner tube wall surfacos.

$=(1.370+1.730) / 2$

$=1.55 \mathrm{ft} .^{2}$

$h_{s}=2000 \mathrm{Btu} / \mathrm{hr} \cdot \mathrm{xft} .^{2} \mathrm{x}_{\mathrm{F}}$

$x_{w}=$ equivalent wall thickness

= mean of tube wall thickness and one-half the fin longth.

$=0.095+0.500 / 2$

$=0.345 \mathrm{in}$.

$=0.02875 \mathrm{ft}$. 


$$
\begin{aligned}
k_{s} & =\text { thermal conductivity of steel } \\
& =26 \mathrm{Btu} / \mathrm{hr} . \mathrm{x} \mathrm{ft}^{2} \mathrm{x} \mathrm{o}_{\mathrm{F}} / \mathrm{ft} .
\end{aligned}
$$

The equivalent wall thicknoss $x_{w}$ was calculated assuming that the tube wall must transfer all of the heat either to the oil or to the base of the fins. The heat transferred by the fins must pass through the base of the fins; however, approximately one-half of the total heat transferred by the fins is transferred in the lower half of the fin, and the other half by the upper half. To approximately account for this condition the equivalent wall thickness was taken as the arithmetic mean of the mean tube wall thickness and one-half of the fin height. Then:

$$
\begin{aligned}
1 / \mathrm{h} & =\frac{1 / \mathrm{U}-11.63 /(2000)(1.370)-(0.02875)(11.63) /(26)}{(1.55)} \\
& =1 / \mathrm{U}-0.00425-0.00830 \\
& =1 / \mathrm{U}-0.0126
\end{aligned}
$$

8. Correction of the values of the oil film heat transfer coeficient for the drop in temperature from the base of the fin to the tip.

The values of $h$ may be corrected by dividing the uncorrected values by the ratio $(\Delta t)_{m} /(\Delta t)_{0}$, where: 


$$
\begin{aligned}
(\Delta t)_{m} /(\Delta t)_{0} & =\tanh a x_{f} / a x_{f} * \\
a & =(h b / k s) 0.5 \\
b & =\frac{2(0.5)+0.031}{12} \\
& =0.086 \mathrm{ft} . \\
k & =26 \mathrm{Btu} / \mathrm{hr} . \mathrm{xt.} \mathrm{x}_{\mathrm{F} . / \mathrm{ft} .} \\
\mathrm{s} & =(0.5 \mathrm{x} 0.031) / 12 \\
& =0.001292 \mathrm{ft} .2
\end{aligned}
$$

The following equation was derived for the calculation of the value of $\operatorname{ax}_{\mathrm{f}}$ :

$$
\begin{aligned}
a & =(\mathrm{hb} / \mathrm{ks})^{0.5} \\
\log a & =0.5(\log \mathrm{h}+0.5 \log (\mathrm{b} / \mathrm{ks}) \\
& =0.5 \log \mathrm{h}+0.5 \log (\mathrm{b} / \mathrm{ks}) \\
& =0.5 \log \mathrm{h}+0.5 \log (0.086) /(26)(0.001292) \\
& =0.5 \log \mathrm{h}+0.5 \log 2.56 \\
& =0.5 \log \mathrm{h}+(0.5)(0.4082) \\
& =0.5 \log \mathrm{h}+0.2041 \\
\mathrm{x}_{\mathrm{f}} & =0.5 / 12 \\
& =0.04165 \mathrm{ft} . \\
\log \mathrm{x}_{\mathrm{f}} & =10 \mathrm{~g} 0.04165 \\
& =8.6196-10 \\
& =-1.3804
\end{aligned}
$$

* The source of this equation and the definitions of the terms used are covered in the Theoretical section, pp. (22-23). 


$$
\begin{aligned}
\log a x_{f} & =\log \mathrm{a}+\log \mathrm{x}_{f} \\
& =0.5 \log \mathrm{h}+0.2041-1.3804 \\
& =0.5 \log \mathrm{h}-1.1763
\end{aligned}
$$

Using the uncorrected value of $h$ the value of ax was calculated from the above equation. From a table of hyperbolic funotions (13) the value of tanh ax was obtained, and the ratio $(\Delta t)_{m} /(\Delta t)_{0}$ calculated from tanh $a x_{f} / a x_{f}$. The uncorrected value of $h$ was then corrected by dividing by the ratio $(\Delta t)_{m} /(\Delta t)_{0} \cdot(4)$

9. The calculation of the dimensionless groups is selfexplanatory in Table IIB. 
ACKNOWLDDGMIT 
The Author wishes to acknowlodge the kind assistance and guidance of Dr. R. C. Ernst, the director of this investigation. Sincere thanks are also extended to the Henry Vogt Machine Company and the Standard Oil Company of Kentuciry for providing equipment for this investigation, and to Mr. Melvin Sack for his helpful suggestions. 
VITA 
Boyd Rieman Abbott, Jr.

The Author is the son of Boyd Rieman Abbott and Therese Hadacek Abbott, and was born in Somerville, New Jersey, on the ninth of February, 1921. He attended the Theodore Roosevelt grade school, the Rittenhouse Junior High School, and the Norristown Senior High School, of Norristown, Pennsylvania, being graduated from the latter in June, 1938.

He recelved the degree of Bachelor of Science in Chemical Engineering from the Worcester Folytechnio Institute, Worcester, Massachusetts, in May, 1942. His undergraduate thesis was concerned with the humlification of air, and was directed by Dr. Ernest Dana Wilson, head of the Department of Chemical Engineering at the Worcester Polytechnic Institute.

He has had industrial experience with the American Lacquer Solvents Company of Phoenixville, Pennsylvania, the Alan Wood Steel Company of Conshohocken, Pennsylvania, and with Joseph E. Seagram \& Sons, Inc. of Louisville, Kentucky. 